\title{
TEXTURE OF EXTRA VIRGIN OLIVE OIL-ENRICHED MASHED POTATOES: SENSORY, INSTRUMENTAL AND STRUCTURAL RELATIONSHIPS
}

3

4

\section{5}

6

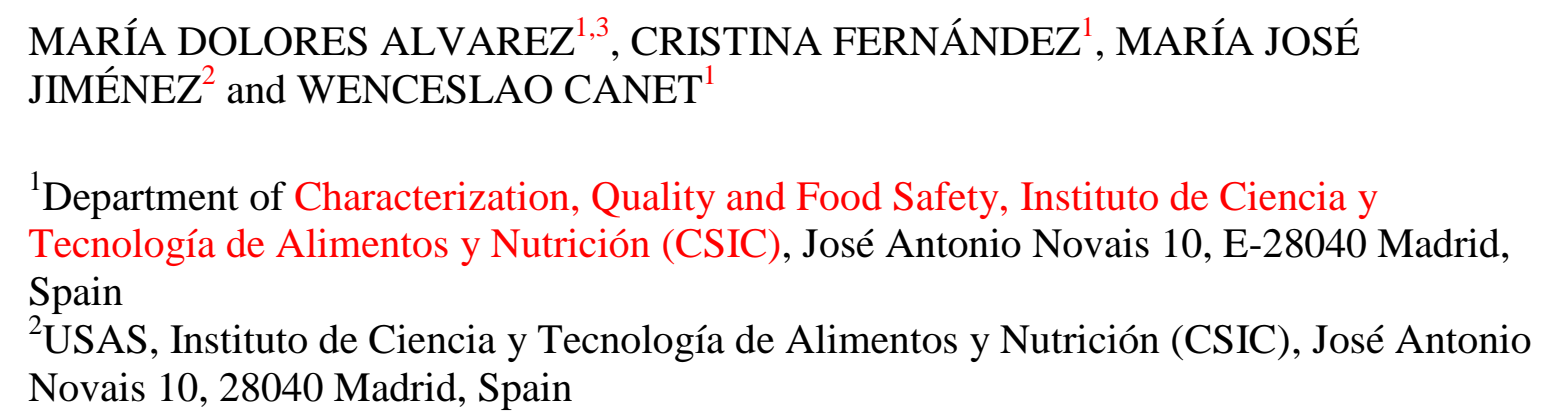

\section{Running title}

OLIVE OIL EFFECT ON MASHED POTATO TEXTURE

${ }^{3}$ Corresponding author. TEL: +34-91-5492300; FAX: +34-91-5492300;

EMAIL:mayoyes@ictan.csic.es 


\section{ABSTRACT}

The aim of this work was to study the effect of the addition of extra virgin olive oil (EVOO) on instrumental textural properties, sensory texture profile analysis (TPA) and microstructure of fresh and frozen/thawed mashed potatoes formulated without and with added cryoprotectants [kappa-carrageenan $(\kappa-\mathrm{C})$ and xanthan gum $(\mathrm{XG})]$. EVOO behaves as soft filler due to droplet aggregates, whereas addition of cryoprotectants led to more structured mashed potatoes (MP) thanks to the gelling properties of $\kappa$-C. Both the percentage of added EVOO and processing had a much less significant effect on the texture of the MP containing $\kappa$-C and $\mathrm{XG}$, evidencing the ability of this biopolymer blend to impart freeze/thaw stability. All samples with added EVOO were perceived as significantly softer and creamier than the samples without EVOO, whereas all MP samples with added cryoprotectants were perceived as significantly thicker and creamier than those without hydrocolloids.

\section{KEYWORDS}

Extra virgin olive oil, mashed potatoes, texture, microstructure, TPA sensory attributes, freezing 
53 Previous studies showed that the quality after freezing and thawing may be improved by 54 the addition of $1.5 \mathrm{~g} / \mathrm{kg}$ of $\kappa-\mathrm{C}$ and $1.5 \mathrm{~g} / \mathrm{kg}$ of $\mathrm{XG}$, and/or incorporation of dietary fiber, 55 improvement of mashed potatoes texture by retarding starch retrogradation and increasing 56 water-holding capacity. Growing awareness of the link between diet and health is fast 57 changing consumer habits, so that there has been increasing demand for foods with health 58 enhancing properties. Extra virgin olive oil (EVOO) has important nutritional 59 characteristics linked to its biophenol content and has very important antioxidant 60 properties. The results have shown that although instrumental textural data were able to 61 explain differences in consistency perceived, structural information is needed to 62 understand differences in creaminess. Back extrusion test is recommended to industry as 63 practical quality control tool in the commercial production of mashed potatoes with added

64 EVOO.

65 
Various health organizations recommend a daily intake of around $600 \mathrm{~g}$ of fruit and vegetables, but few people manage to consume this amount. Led by consumer demand, the food industry has shown an increased interest in the manufacture of healthier and more natural fruit and vegetable food products, such as soups, drinks and sauces (Whybrow et al. 2006). Mashed potatoes (MP) made from $100 \%$ fresh potato tubers are in addition a natural vegetable semisolid food, which may also be suitable for freezing as a ready-meal component or as a product in itself such as potato gratin (Alvarez et al. 2009).

Olive oil is an important component of the diet of the countries surrounding the Mediterranean Sea. Due to its composition, olive oil is a good source of biophenols (Boskou and Visioli 2003) as well as lipid-soluble and water-soluble vitamins (tocopherols, $\beta$-carotene, ascorbic acid). In addition, thanks to its balanced fatty acid composition virgin olive oil has highly appreciated nutritional characteristics (MildnerSzkudlarz and Jelen 2010), known for a long time to the people of the Mediterranean region, who use it daily for a variety of culinary purposes. Biophenols with important antioxidant properties and a role in atherogenesis and cancer have been found and quantified in virgin and extra-virgin olive oils (Muniz 2007). However, consumption has also increased in non-Mediterranean areas thanks to growing interest in the Mediterranean diet and a belief that it prevents certain diseases (Boskou and Visioli 2003; 86 Paraskevopoulou et al. 2005). A classic white sauce usually contains flour, milk and butter, but olive oil has been added to a white model-sauce to produce an innovative sauce approximating "Mediterranean cooking” (Mandala et al. 2004).

The oil volume fraction exerts profound effects on the physicochemical and 90 viscoelastic properties of emulsions, such as droplet size distribution, creaming, oxidative 
stability, and rheology (Dickinson and Chen 1999). Fat droplets influence the overall physicochemical and sensory properties of foods in a variety of different ways (Chantrapornchai et al. 1999). A great deal of research has been done on the influence of fat droplets on the rheology, stability and flavour of food emulsions, but less is known about their influence on emulsion appearance. Color is one of the major attributes affecting consumer perception of the quality of virgin olive oil (Criado et al. 2008), and chloroplast pigments (chlorophyll and carotenoids) are mainly responsible for the color of virgin olive oil, ranging from yellow-green to greenish gold (Ayuso et al. 2004).

Texture is by far the most important quality criterion for consumer sensory acceptance of freshly prepared and processed potato products, and particularly of frozen/thawed and dehydrated mashed potatoes. A fluffy and medium-consistency texture is desirable, whereas pastiness, gumminess and stickiness are negative attributes (Lamberti et al. 2004). Texture instability remains the most significant challenge for frozen food products, especially with inevitable post-production temperature fluctuations. Loss of moisture and changes in textural attributes often result in significant reduction of product quality.

Previous studies showed that the addition of $\kappa-\mathrm{C}$ and XG to MP at a low concentration (each cryoprotectant at $1.5 \mathrm{~g} / \mathrm{kg}$ ) is recommendable on the basis of overall acceptability, especially when the product is going to be frozen (Alvarez et al. 2009; Fernández et al. 2009). $\kappa$-C provides the appropriate texture, while XG imparts creaminess and mouthfeel to the product.

No research has been done on the addition of olive oil in fresh and frozen/thawed mashed potatoes (designated FMP and F/TMP respectively), particularly with EVOO. The use of EVOO rather than commercial olive oil is preferable because of its high concentrations of both unsaturated fatty acids and antioxidant compounds such as polyphenols and tocopherols (Severini et al. 2003). The purpose of the present research 
116 was to evaluate the effects of adding EVOO on the textural, physical, structural and

117 sensory characteristics of fresh and frozen/thawed mashed potatoes formulated without and 118 with added cryoprotectants.

\section{MATERIALS AND METHODS}

\section{Materials}

The potatoes used were fresh tubers (cv Kennebec) from Aguilar de Campoo (Burgos, Spain) grown in 2008. $\kappa$-C (GENULACTA carrageenan type LP-60) and XG (Keltrol F [E]) were donated by Premium Ingredients, S.L. (Girona, Spain). EVOO (Carbonell, Spain) was chosen for addition to the MP. Following range-finding experiments, the lower and upper levels of EVOO to be used were set at 10 and $50 \mathrm{~g} / \mathrm{kg}$, respectively. A sample without EVOO was also prepared for each type of MP and processing conditions.

\section{Preparation of MP Samples}

Tubers were manually washed, peeled and diced. MP were prepared in 2000-g batches

134 from $607.7 \mathrm{~g} / \mathrm{kg}$ of potatoes, $230.8 \mathrm{~g} / \mathrm{kg}$ of semi-skimmed in-bottle sterilized milk (fat 135 content, $15.5 \mathrm{~g} / \mathrm{kg}), 153.8 \mathrm{~g} / \mathrm{kg}$ of water, $7.7 \mathrm{~g} / \mathrm{kg}$ of salt $(\mathrm{NaCl})$ and the corresponding 136 EVOO concentration $(0,10,25$, and $50 \mathrm{~g} / \mathrm{kg}$ ) using a TM 31 food processor (Vorwerk

137 España, M.S.L., S.C., Madrid, Spain). MP were prepared without and with added $\kappa$-C and 138 XG (MPA and MPB samples, respectively). In the latter case, hydrocolloids (each at 1.5 $139 \mathrm{~g} / \mathrm{kg}$ ) were also added to the rest of the ingredients in the form of a dry powder. All the 140 ingredients were cooked for $35 \mathrm{~min}$ at 90C (blade speed: $40 \mathrm{rpm}$ ) (Alvarez et al. 2009; 
141 Fernández et al. 2009). The mash was ground for $40 \mathrm{~s}$ (1200 rpm) and for $20 \mathrm{~s} \mathrm{(2600} \mathrm{rpm).}$

142 The product was at once homogenized through a stainless steel sieve (diameter: $1.5 \mathrm{~mm}$ ).

143 The highest EVOO concentration was added twice to the MP to evaluate the effect of order

144 of addition and EVOO thermal treatment on MP quality. First, $50 \mathrm{~g} / \mathrm{kg}$ of EVOO was

145 added along with the rest of the ingredients as indicated above, whereas in the second case

146 the same EVOO concentration (designated " $50 \mathrm{~b}$ " $\mathrm{g} / \mathrm{kg}$ ) was added to the MP before final

147 homogenization. Half of each fresh blend (FMP samples) was analysed immediately and

148 the other half was frozen and thawed (F/TMP samples). Two repetitions of each

149 composition were prepared in different weeks.

151 Freezing, Thawing and Heating Procedures

152

153 MP samples were placed on flat freezing and microwave thawing trays, and then frozen by

154 forced convection with liquid nitrogen vapour in an Instron programmable chamber (model

$1553119-05,-70 /+250 \mathrm{C})$ at -60C until their thermal centres reached -24C (Fernández et al.

156 2009). After freezing, the samples were packed in polyethylene plastic bags, sealed under

157 light vacuum (-0.05 $\mathrm{MPa})$ on a Multivac packing machine (Sepp Haggenmüller KG,

158 Wolfertschwenden, Germany), and placed in a domestic freezer for storage at $-24 \mathrm{C}$.

159 Packed frozen samples were thawed in a Samsung M1712N microwave oven (Samsung

160 Electronics S.A., Madrid, Spain). Samples were heated for $20 \mathrm{~min}$ at an output power

161 rating of $600 \mathrm{~W}$. Samples were brought up to 55C by placing them in a Hetofrig CB60VS

162 water bath (Heto Lab Equipment A/S, Birker $\varnothing$ d, Denmark). Sample testing was 55C,

163 where water and product temperatures were monitored by T-type thermocouples as

164 described elsewhere (Alvarez et al. 2005, 2008, 2009; Fernández et al. 2008). 
Back extrusion (BE) and cone penetration (CP) mechanical tests were performed in order to study the empirical rheological behavior of "semisolid like" samples. Both experiments were performed using a TA.HDPlus Texture Analyser (Stable Micro Systems Ltd,

171 Godalming, UK) equipped with a $300 \mathrm{~N}$ load cell. During tests, MP samples were kept at

$17255 \mathrm{C}$ by means of a Temperature Controlled Peltier Cabinet (XT/PC) coupled to a separate

173 heat exchanger and proportional-integral-derivative control unit. For performance of BE

174 tests, a rig (model A/BE, Stable Micro Systems) was used consisting of a flat $45 \mathrm{~mm}$

175 diameter perspex disc plunger that was driven into a larger perspex cylinder sample holder

176 (50 mm diameter) to force down into the MP samples and flow it upward through the

177 concentric annular space between plunger and the container. The measuring cup was filled

178 with $50 \pm 1 \mathrm{~g}$ of MP. Product was extruded to a distance of $20 \mathrm{~mm}$ at $2 \mathrm{~mm} / \mathrm{s}$ compression

179 rate. At this point (most likely to be the maximum force), the probe returns to its original

180 position. From the recorded force time curves, texture parameters with physical meaning

181 are calculated, which vary from simple consistency indices to a derived flow behavior

182 index, which is obtained according to the mathematical model suggested by Osorio and

183 Steffe (1987). In this study, maximum positive force of extrusion (firmness (N)) and the

184 negative area of extrusion (viscosity index $(\mathrm{N} \mathrm{s})$ ) have been taken into account in order to

185 describe texture changing in MP samples. For performing the CP tests, a TTC spreadability

186 rig (HDP/SR, Stable Micro Systems) was used, consisting of a 45 degree conical perspex

187 probe $(\mathrm{P} / 45 \mathrm{C})$ that penetrated a conical sample holder containing $7 \pm 0.1 \mathrm{~g}$ of MP product.

188 Product was penetrated to a distance of $17.5 \mathrm{~mm}$ at $3 \mathrm{~mm} / \mathrm{s}$ compression rate. $\mathrm{CP}$ work per

189 displaced volume $\left(\mathrm{J} / \mathrm{m}^{3}\right)$ required to accomplish penetration was calculated from the area

190 under the curve up to the "peak" or maximum penetration force, and the average force of 
191 the complete curve $(\mathrm{N})$ was also recorded. Texture measurements were performed in

192 quadruplicate and results averaged.

\section{Other Quality Parameters}

196 The color of the MP in the pots was measured with a HunterLab model D25 (Reston, VA,

197 USA) color difference meter fitted with a $5 \mathrm{~cm}$ diameter aperture. Results were expressed 198 in accordance with the CIELAB system with reference to illuminant D65 and a visual 199 angle of $10^{\circ}$. The parameters determined were $L^{*}, a^{*}$ and $b^{*}$. A higher $L^{*}$ value indicated 200 a brighter or whiter sample and values of $a^{*}$ and $b^{*}$ indicated red-green and yellow-blue 201 colors. Yellowness index (YI) was calculated as 142.86b*/L* (Fernández et al. 2008). Expressible water $\left(E_{\mathrm{w}}\right)$ was measured by centrifugal force. Centrifuge tubes containing approximately $10 \mathrm{~g}$ of MP were centrifuged at $15,000 \times \mathrm{g}$ for $30 \mathrm{~min}$ in a Sorvall ${ }^{\circledR}, \mathrm{RC}-5 \mathrm{~B}$ apparatus (Global Medical Instrumentation, Inc, Clearwater, Minnesota, USA). $E_{\mathrm{w}}$ was expressed as the percentage of liquid separated per total weight of sample in the centrifuge tube (Eliasson and Kim 1992). Measurements of color and $E_{\mathrm{w}}$ were performed in quadruplicate and the results averaged.

\section{Sensory Analyses}

211 MP samples were subjected to texture profile analysis (TPA) modified to evaluate 212 vegetables purees according to UNE 87025 (1996), which was used to select and define the 213 sensory attributes included in the profile. A panel of 4 assessors, previously trained 214 according to the ISO guidelines (ISO 8586-1:1993) and with specific exercise in MP for 8 215 years (Alvarez et al. 2005, 2008; Fernández et al. 2008), evaluated the textural attributes of 
216 the samples. Profile attributes were classified into four groups (Alvarez et al. 2008).

217 Attributes are listed in the order of the perception according to ISO guidelines (ISO 13299:

218 2003): attributes perceived before putting the sample in mouth (granularity and moisture

219 (1)); attributes perceived at the time of putting the sample in the mouth (stickiness, 220 denseness, homogeneity, moisture (2) and firmness); attributes perceived at the time of 221 preparing the sample in the mouth for swallowing (cohesiveness, adhesiveness and 222 fibrousness (1)); attributes perceived during final and residual phases of mastication (ease 223 of swallowing, palate coating and fibrousness (2)). A description of the sensory attributes 224 evaluated during the TPA can be found elsewhere (Alvarez et al. 2008).

Samples were evaluated, in duplicate, in morning sessions (11:00 a.m.-1:00 p.m.). Daily for 40 days assessors were given four samples (about $20 \mathrm{~g}$ each), for scoring attributes of each group in the texture profile. All the samples were served at $55 \pm 1 \mathrm{C}$ on Petri dishes. This sample temperature was reached and kept constant by placing the product in the Hetofrig CB60VS water bath prior to testing. For each sample, panelists evaluated the perceived intensity of the 13 attributes on $8 \mathrm{~cm}$ descriptive linear scales

231 labelled at each anchor: (left anchor: $1=$ "not detectable; right anchor: 9 = "extremely 232 intense'). To reduce fatigue a rest period of 5 min was taken after scoring each sample.

MP samples were also subjected to an overall acceptability (OA) test based on all sensory attributes (texture, color, taste) on a 9-point hedonic scale (with $8 \mathrm{~cm}$ ) labelled at each anchor: (left anchor: 1 = "dislike extremely"; right anchor: 9 = "like extremely"). In this case, sensory assessment was conducted by a 14-member untrained panel. Every day, one sample (about $20 \mathrm{~g}$ each) was served under the same conditions as indicated above. 
241 MP microstructure was examined by SEM using a Hitachi model S-2.100 microscope 242 (CENIM-CSIC). MP samples were air-dried, then mounted and sputter-coated with Au 243 (200 A aprox.) in a SPI diode sputtering system metallizer. Photomicrographs were taken 244 with a digital system Scanvision 1.2 of RONTEC (800x1.200 pixel).

\section{Statistical Analysis}

248 A three-way ANOVA with interactions was applied to evaluate how the three factors 249 studied-EVOO concentration, presence or absence of hydrocolloids and performance or 250 not of processing — affected the texture, color, sensory attributes and the OA of the MP. $251 E_{\mathrm{w}}$ was always zero for the MPB samples; a two-way ANOVA with interactions was 252 applied to evaluate how EVOO concentration and processing affected the $E_{\mathrm{w}}$ of the 253 products. Minimum significant differences were calculated using Fisher's least significant 254 difference test (LSD, 99\% for comparison of instrumental parameters and 95\% for 255 comparison of sensory attributes and OA). Analyses were performed with Statgraphics ${ }^{\circledR}$ 256 software version 5.0 (STSC Inc., Rockville, MD, USA). 


\section{RESULTS AND DISCUSSION}

259

260

261

262

263

264

265

\section{Instrumental Texture Measurements}

Table 1 shows the effects of EVOO concentration, cryoprotectant addition and processing on the values of the textural properties derived from the BE and CP tests. Samples with added $\kappa$-C and $\mathrm{XG}$, as well as those subjected to freezing/thawing, presented significantly higher and lower textural properties than their respective counterparts. Previous studies showed that when $\kappa$-C/XG blends were added to FMP and F/TMP samples, $\kappa$-C provided the appropriate texture whereas XG imparted creaminess to the product (Alvarez et al. 2009; Fernández et al. 2009; Alvarez et al. in press). Analogously, in starch/XG blends, it was observed that XG does not interfere in potato starch network building (Mandala and Palogou (2003); Mandala et al. 2004). Therefore, addition of both hydrocolloids to MP produces a more structured system which is associated with the gelling properties of $\kappa$-C. In natural MP, the product was softer than the fresh control after freezing and thawing (Alvarez et al. 2005). MP is a starchy food, and as such may present quality problems such as syneresis and organoleptic and textural changes. These problems have been ascribed to phase separation caused by retrogradation of the starch (Eliasson and Kim 1992; Kim and Eliasson 1993).

With respect to the effect of EVOO addition, the maximum textural property values were registered in the samples without EVOO, although differences between textural properties of samples with $10 \mathrm{~g} / \mathrm{kg}$ added EVOO and those without EVOO were nonsignificant (Table 1). However, increasing EVOO concentration produced softer, liquidlike systems, indicating that EVOO behave as soft filler. This result is to be expected as increasing concentrations of liquid oil are added to the product, increasing the oil-phase 
volume fraction. In oil-in-water emulsions, the extent of the linear region decreased with 287 increasing oil-phase volume fraction from $20 \%$ to $40 \%$ v/v (Sun and Gunasekaran 2009). 288 For their part Dickinson and Chen (1999) suggested that oil/water emulsions may undergo 289 a behaviour transition from predominantly entropic behaviour to predominantly enthalpic 290 behaviour with increasing oil-phase volume fraction.

291 The analysis of variance also showed that the three binary interactions had a significant 292 effect on instrumental firmness, work per displaced volume and average force (Table 1). 293 This means that the effect of EVOO concentration on the texture depended on the presence 294 of $\kappa$-C and $\mathrm{XG}$ and on the freezing/thawing of the systems. Besides, $\mathrm{AB}$ and $\mathrm{BC}$ 295 interactions also significantly affected the viscosity index from the BE tests.

296 From the variation in the firmness value based on EVOO concentration for both MPA 297 and MPB samples shown in Fig. 1a, one can observe that firmness was lower in the MPA 298 than in the MPB samples; moreover, the variation in sample firmness was much greater 299 when EVOO content increased from 10 to $50 \mathrm{~g} / \mathrm{kg}$ in the MPA samples than in the MPB 300 ones. Also, when the concentration of added EVOO was increased, the firmness value 301 behaved similarly in the FMP and F/TMP samples (Fig. 1b); in both cases, the increase in 302 EVOO content led to reduced firmness, without important differences between 50 and $50 \mathrm{~b}$ 303 $\mathrm{g} / \mathrm{kg}$. As droplet concentration increases, the droplets are polydispersed and the samples present a less close packing structure. In mayonnaise, increasing walnut oil content increases the diameter of oil droplets and consequently reduces viscoelastic properties 306 (Cavella et al. 2009). From the variation in the firmness based on processing, the firmness 307 value developed differently for the MPA and MPB samples (Fig. 1c). Processing 308 significantly reduced sample firmness in the MPA samples but significantly increased it in 309 MPB samples. This behaviour can be explained taking account that much stronger and 310 more cohesive networks are formed when solutions of XG are frozen and thawed 
311 (Giannouli and Morris 2003). The effect of XG may be explained by amylose/XG 312 interactions, which compete against amylose/amylose interactions, retarding or even 313 preventing retrogradation. Also, the addition of small amounts of XG to white sauces made

314 with starches from different sources significantly improves freeze/thaw stability (Arocas $e t$ 315 al. 2009).

316 In turn, the variation in average force with EVOO concentration for both MPA and 317 MPB samples (Fig. 1d) was similar to that observed in firmness. In this case, of the MPB 318 samples, the ones with $25 \mathrm{~g} / \mathrm{kg}$ EVOO added had poorer consistency, whereas in the MPA 319 systems, the ones with $50 \mathrm{~g} / \mathrm{kg}$ had poorer consistency. When the EVOO concentration was 320 increased the average force decreased in both FMP and F/TMP samples (Fig. 1e), although 321 in the latter case adding $10 \mathrm{~g} / \mathrm{kg}$ EVOO slightly increased the average force as compared 322 with the control without EVOO. Both the BE firmness and the $\mathrm{CP}$ average force values were greater when the EVOO was added after cooking $(50 \mathrm{~b} / \mathrm{kg})$ in the FMP samples but not in the F/TMP samples. When the processing-dependent variation in average force was plotted (Fig. 1f), the changes in that value were also similar to those observed for firmness

326 (Fig. 1c). Plots for the viscosity index and the work per displaced volume have been omitted for the sake of brevity.

\section{Color Measurements and Expressible Water}

331 All the three factors studied significantly changed the color parameters, although 332 processing did not significantly affect the yellowness index (YI) (Table 2). An increase in 333 EVOO level favours higher $L^{*}$ value (lightness) due to an increase in the overall light 334 scattering associated with the scattering properties of fat (Chantrapornchai et al. 1999). As the EVOO concentration increased there was an increase in redness (decreasingly negative 
$a^{*}$ values) and in yellowness (YI), associated with the augmented pigment content of the

MP. The pigment profile of the virgin olive oil comprises chlorophyll a, chlorophyll $b$, and derivative pigments associated with the acidic medium of the oil extraction process (Criado et al. 2008).

$L^{*}$ increased when $\kappa$-C and $\mathrm{XG}$ were added to the MP, which could be partially due to their absolute water-holding capacity (WHC) as discussed below. Also, $a^{*}$ was higher in 342 the MPB than in the MPA samples, indicating significant raised sample redness. The loss 343 of greenness associated with cryoprotectant addition was probably due to the presence of $344 \mathrm{XG}$ in the system as found previously (Fernández et al. 2008). Increased lightness in the 345 F/TMP samples as compared to their FTM counterparts may have been partly due to the 346 formation of fissures produced by the growth of ice crystals during freezing, which favours 347 the release of water; this would transmit the light more rather than capturing it. For its part 348 the loss of greenness found in the processed samples ( $a^{*}$ values nearer to 0 ) as compared to 349 the fresh counterparts could be due to slight non-enzymatic browning (Maillard reaction) 350 during microwave thawing.

351 On the other hand, the three interactions had a significant effect on $L^{*}$ and YI (Table 352 2). Moreover, $\mathrm{AB}$ and $\mathrm{AC}$ interactions significantly affected the $a^{*}$ value. The variation in 353 the $L^{*}$ value based on EVOO concentration in both MPA and MPB samples (Fig. 2a) 354 shows that increased EVOO concentration produced an increase in the $L^{*}$ value in both 355 samples. The influence of droplet characteristics on the optical properties of colored oil-in356 water emulsions has been studied (Chantrapornchai et al. 1999). The lightness of the 357 emulsions increased with increasing droplet concentration and decreasing droplet size. As 358 the droplet concentration increases so does the reflectance because the droplets scatter light 359 more effectively and hence the light beam is unable to penetrate further into the product 360 and be absorbed. 
The differences between the $L^{*}$ values of the MPA samples and their MPB counterparts increased with increasing the EVOO content (Fig. 2a). In emulsions, XG is added to the aqueous phase to prevent droplets from rapidly creaming and coalescence 364 (Parker et al. 1995; Sun and Gunasekaran 2009). In this study oil droplet diameters were not measured, but it is probable that the droplets in the MPB samples were smaller than in the ones without cryoprotectants as the presence of $\mathrm{XG}$ in the system would prevent 367 coalescence. The reason why the $L^{*}$ values were lower in the MPA samples, then, is that 368 reflectance decreases with increasing droplet diameter. Note that in the MPB samples the $L^{*}$ value was greater when the EVOO was added after cooking $(50 \mathrm{~b} \mathrm{~g} / \mathrm{kg})$, whereas in the MPA systems it was greater in the samples with $50 \mathrm{~g} / \mathrm{kg}$ EVOO added before cooking. This discrepancy could also be related to the presence of cryoprotectants in the system. MP 372 with EVOO added before final homogenization would be expected to have larger droplets 373 because the oil was not thoroughly triturated. In the presence of XG, the droplets scatter

374 light more effectively when the oil is not so strongly entrapped in the matrix. In the MPA samples on the other hand, reflectance probably decreased because the scattering efficiency 376 of the droplets decreases above a certain droplet size (Chantrapornchai et al. 1999). In turn, as the droplet concentration increases, more reflected light travels through the 378 oil phase of the MP being absorbed by the pigments mentioned earlier, intensifying the 379 color of the MP (Figs. 2b, c). However, as regards YI values, there were small differences 380 between FMP and F/TMP samples. Anyway, the color differences found between samples, 381 although significant, should not be of major importance in practical terms.

$382 E_{\mathrm{w}}$ changed significantly with EVOO concentration and processing (Table 2), and the 383 AC interaction had a significant effect on the WHC of the samples (Fig. 2d). In this study, 384 addition of $\kappa-\mathrm{C}$ and $\mathrm{XG}$ reduced the $E_{\mathrm{w}}$ of both FMP and F/TMP samples to $0 \%$, 385 corroborating the well-established ability of XG to reduce water separation (Alvarez et al. 
2008, 2009; Arocas et al. 2009), and evidencing the existence of XG-water or XG-water-

$387 \mathrm{XG}$ interactions in the systems. $\mathrm{XG}$ is an anionic, hygroscopic material of exceptional 388 pseudoplasticity (Baranowska et al. 2008); its texturizing effect can be achieved at low 389 gum concentration because of unusual water-holding ability. Also, adding XG ( $0.3 \%$ w/w) 390 to corn starch pastes $(10 \% \mathrm{w} / \mathrm{w})$ minimized amylose retrogradation, syneresis and 391 rheological changes after freezing (Ferrero et al. 1994). Certainly, the $E_{\mathrm{w}}$ values confirm 392 that XG effectively stabilizes MP against syneresis when no more than $1.5 \mathrm{~g} / \mathrm{kg}$ is added.

Besides, WHC was greater in the FMP samples than in their F/TMP counterparts at all 394 EVOO concentrations (Fig. 2d). This result is probably related to structural damage caused 395 by freezing. The addition of EVOO at low concentrations significantly increased $E_{\mathrm{w}}$, 396 mainly in the processed samples, which is likely due to that the interchain spaces were 397 occupied by oil, displacing the water (Liehr and Kuliche 1996). However, the addition of 398 EVOO at higher concentrations significantly reduced water loss, probably because excess 399 oil hindered the release of water from the starch matrix. EVOO by itself was not effective 400 in enhancing the WHC of MP. In any case $E_{\mathrm{w}}$ percentages were also quite high (> 20) in 401 both FMP and F/TMP samples without added EVOO, evidencing the presence of weak 402 starch-water or starch-water-starch interactions in all the systems. Water separation in the 403 MPA samples is related to starch retrogradation and consequent reduction of WHC 404 (BeMiller and Whistler 1996).

406 Sensory Analyses

407

408 Attributes perceived before putting the sample in mouth. All the three main factors and 409 their interactions significantly $(P<0.05)$ affected the scores for granularity and moisture 410 (1) (Table 3). One can observe that at all EVOO concentrations granularity scores were 
411 greater in the MPA samples (Fig. 3a) and likewise in the fresh products (Fig. 3b).

412 Christianson et al. (1981) indicated that gums like XG affect the gelatinization and

413 retrogradation of starch through strong associations with amylose, resulting in reduced

414 amylose-amylose interactions. In turn, presence of XG reduced granularity in the F/TMP

415 systems by assisting new starch/water interactions and consequent water absorption. In

416 both MPA and MPB samples, panelists judged granularity lowest in the samples with more

417 than $10 \mathrm{~g} / \mathrm{kg}$ added EVOO. The effects of EVOO on granularity are related to the

418 lubricating and coating properties conferred by the oil as reported for vanilla custard

419 desserts (de Wijk et al. 2003).

420 In turn, moisture (1) decreased significantly with respect to MPA samples with the 421 addition of cryoprotectants in both FMP and F/TMP (Fig. 3c). Panelists detected greater 422 ability to hold water molecules in MPB samples, confirming the results for $E_{\mathrm{w}}$ values. 423 Similarly, panelists detected less aqueousness in the processed samples than in the fresh 424 ones, probably due to water loss.

426 Attributes perceived at the time of putting the sample in the mouth. Stickiness scores 427 were significantly higher in the MPB samples, although there were no differences in these 428 scores as a consequence of EVOO concentration or processing (Table 3; Fig. 3d). In turn, 429 the three factors significantly affected scores for denseness, homogeneity, moisture (2) and 430 firmness. Denseness was significantly higher in the processed than in the fresh samples 431 only when EVOO was added at the highest concentrations (Fig. 3e). Also, denseness was 432 lower in the MPA than in the MPB samples (Fig. 3f), and only in this latter case were 433 denseness scores significantly higher in the F/TMP samples than in their FMP 434 counterparts. 
When EVOO concentration was increased, homogeneity increased in both MPA and 436 MPB samples (Fig. 3g). Note that the presence of EVOO in the systems rendered 437 differences in homogeneity among MPA and MPB samples less appreciable. Also, when 438 EVOO concentration was increased (Fig. 3h), homogeneity increased in the FMP products 439 but was almost constant in the processed samples. This indicates a positive effect of adding 440 EVOO to MP, since the negative effect of freezing on this attribute is masked by the oil. 441 Panelists detected reduced moisture (2) in the MPB samples and in the processed systems, 442 and when the EVOO concentration was increased, moisture (2) significantly increased 443 when cryoprotectants were also added (Fig. 3i).

444 In turn, panelists detected reduced firmness in the samples with added EVOO, without 445 added cryoprotectants and without processing. One can observe that the processed samples 446 with the lower and higher EVOO concentrations were the firmest, whereas in the systems with $25 \mathrm{~g} \mathrm{~kg}^{-1}$ added EVOO the fresh samples had similar firmness than the control (Fig. 4a). In the MPA samples there were no differences between firmness scores in fresh and processed samples (Fig. 4b); however, panelists detected increased firmness in processed MP with added $\kappa$-C and $\mathrm{XG}$, matching the result for textural properties in MPB samples $451 \quad$ (Figs. 1c,f).

Attributes perceived at the time of preparing the sample in the mouth for swallowing. EVOO concentration, cryoprotectant addition and processing also had a significant effect on cohesiveness, adhesiveness and fibrousness (1) (Table 3). When EVOO concentration 456 was increased, cohesiveness and adhesiveness scores decreased significantly in the MPB samples (Figs. 4c,d). In the MPA samples there were no significant differences between 458 the adhesiveness scores of fresh and processed samples (Fig. 4e), whereas panelists scored 459 the processed MPB samples higher for adhesiveness than their fresh counterparts. Scores 
for fibrousness (1) also decreased with increasing EVOO concentration, with

461 cryoprotectant addition and with processing (Figs. 4f,g). Again, addition of cryprotectants

462 reduced differences in fibrousness (1) between fresh and processed samples. This is

463 probably related to the fact that the hydrocolloids can make systems in the rubbery state

464 more viscous, reducing molecular mobility and preventing retrogradation (Ferrero et al. 465 1994).

Attributes perceived during final and residual phases of mastication. The three factors studied had a significant effect on ease of swallowing and fibrousness (2) (Table 4), whereas only EVOO concentration had a significant effect on palate coating. In samples both without and with added cryoprotectants (Fig. 4h) and in both FMP and F/TMP samples (Fig. 4i), ease of swallowing scores increased with increasing oil content. However, only when EVOO was added at concentrations of 0 and $10 \mathrm{~g} / \mathrm{kg}$, the scores for 473 this attribute were higher in the samples without cryoprotectants and in the processed 474 samples. Panelists also scored the samples with added EVOO significantly higher for 475 palate coating than the ones made without EVOO (Figs. 5a,b). Scores for palate coating 476 were higher in the MPA samples with 25 and $50 \mathrm{~g} / \mathrm{kg}$ added EVOO than in their MPB counterparts (Fig. 5a), and the EVOO content had a much smaller effect in the F/TMP 478 samples than in the fresh counterparts (Fig. 5b). Palate coating scores for MPA samples 479 decreased after processing whereas scores for MPB samples increased with respect to the 480 fresh products (Fig. 5c). Also, in the MPA samples, the addition of EVOO at all 481 concentrations significantly reduced sample fibrousness (2) (Fig. 5d).

482 A complete dependence study was performed on the instrumental textural properties 483 versus sensory attribute scores. Low correlations between instrumental and sensory ratings 484 were found. Previous publications by other researchers generally agree on good to 
excellent correlations for hardness (based on calculated " $r$ " values (Szczesniak 2002).

486 Correlations for other parameters are usually less good and product-dependent. In this

487 study, relatively good correlations with sensory denseness and adhesiveness scores were 488 found only in the case of viscosity index $\left(\mathrm{R}^{2}=0.81\right.$ and 0.76 , respectively). Differences in 489 consistency observed among samples were explained by viscosity index, but not the 490 variation in granularity or fibrousness, determining the sample creaminess.

Overall acceptability. EVOO concentration, cryoprotectant addition and processing had a significant effect on the OA of the samples (Table 4). Scores for OA increased significantly with increasing EVOO content in both MPA and MPB samples (Fig. 5e), and likewise in both FMP and F/TMP samples (Fig. 5f). Similarly, a positive relationship between oil content and sensory acceptability has been observed in a set of Polish commercial mayonnaises (Juszack et al. 2003) and in salami (Severini et al. 2003). In this study, the main differences between samples without and with added EVOO were ascribed to either an aromatic or a creamy note detected in the oil-added MP. Samples with higher percentages of EVOO produced less sensations of dryness and roughness, more sensations

501 of flavour, creamy and fatty mouth- and after-feel than the samples without added oil. Fat 502 is a well-known enhancer of creaminess sensations (de Wijk et al. 2003). The latter authors suggested that the possible mechanism by which fat affects the sensory attributes include lubrication and flavour release. The effects of fat on odour and flavour attributes may be related to the flavour-releasing properties of fat.

506 Panelists scored the MPB and F/TMP samples higher for OA (Figs. 5e,f). This is 507 probably related to the presence of $\mathrm{XG}$ in the systems. It was found that samples containing blends of $\kappa-\mathrm{C}$ and XG (Alvarez et al. 2009; Fernández et al. 2009), were preferred organoleptically due to the creamy mouthfeel they produced. The effects of XG 
on mouth texture may be related to its WHC as perceived by the panelists. Besides, in the

511 processed MPB samples, there were no significant differences between the OA scores 512 given to the MP at any concentration of added EVOO (which were the highest). This has

513 important consequences for the formulation of EVOO-based MP. Results indicate that in 514 the presence of $\kappa$-C and XG, if the EVOO content is reduced to below $25 \mathrm{~g} / \mathrm{kg}$, the OA 515 score for the product does not decrease, and hence its consumer acceptability is not 516 adversely affected.

\section{Microstructure Examination}

To achieve a better understanding of the sensory and rheological results and the effect of

521 adding cryoprotectants and of freezing/thawing, the microstructure of the MP samples was studied by SEM (Figs. 6, 7). Fig. 6a shows a microphotograph of the fresh control without either added cryoprotectants or oil. Cooked cells are still distinguishable and firmly bound together by a continuous network of amylose. However, in the fresh control without added EVOO but with added cryoprotectants (Fig. 6b), less complete cells are visible, appearing separated from one another and embedded in a continuous network of amylose and $\kappa$-C in which starch granules and XG aggregates are entrapped. Probably, the presence of cryoprotectants occluding a great amount of water probably facilitated loss of the original 529 cell shape.

530 Microphotographs of the corresponding processed counterparts (Figs. 6c,d) show that 531 freezing and thawing of MPA and MPB samples resulted in completely dissolved cells. 532 Part of the intracellular water was drawn out osmotically because of freezing-induced concentration of the cell mass. Cell tearing is probably caused by the formation of ice

534 crystals. Fresh MPA sample contain more complete cells (Fig. 6a), which could give them 
greater mechanical strength; this would justify that the values of the textural properties

536 were higher in fresh MPA samples than in their processed counterparts. In turn, the processed MPA sample without added EVOO (Fig. 6c) developed a spongy appearance due to amylose and amylopectin retrogradation occurring during freezing and frozen storage (Ferrero et al. 1994).

540 The microphotograph of processed MPB sample without added EVOO (Fig. 6d) shows 541 the presence of fibres or strands. According to Giannouli and Morris (2003), during 542 freezing, XG chains are forced to align and associate by conversion of water to ice crystals. 543 The forced associations survive upon thawing to give a cryogel network. It is likely that 544 such strands are related to this XG conformational transition, since they were observed in 545 most of the F/TMP containing cryoprotectants. Formation of strands can be explained by a 546 progressive increase in local concentration of the polymer as liquid water is converted into 547 ice crystals, promoting intermolecular associations.

548 Fig. 7 shows microphotographs of the counterparts of the samples shown in the Fig. 6, 549 but with $50 \mathrm{~g} / \mathrm{kg}$ added EVOO. When EVOO was added, a dispersed thin phase or layer of 550 oil formed, enveloping all the microstructures constituting the MP. Fig. 7a shows some oil 551 droplets in MPA sample, probably formed by aggregation through steric and/or 552 electrostatic forces (Paraskevopoulou et al. 2005), whereas Fig. 7b shows no oil droplets in 553 presence of $\kappa$-C and XG. In MPA samples, freezing also had a negative influence on the 554 formation of oil droplet clusters (Fig. 7c); it is likely that the structural damage caused by 555 freezing enabled the oil droplets to come close enough together to aggregate. 556 Microphotograph of the processed sample with $50 \mathrm{~g} / \mathrm{kg}$ added EVOO (Fig. 7d) shows that 557 white gel structures are also discernible in the presence of cryoprotectants.

558 Addition of XG to salad dressings induces depletion flocculation of the droplets and 559 formation of a three-dimensional weak gel network structure that retards the process of 
droplet creaming (Parker et al. 1995). Adding a hydrocolloid causes protein-coated

561 droplets to aggregate and be excluded from the region of continuous phase between them.

562 Therefore, in the MP with added $\kappa$-C and XG and oil, the XG may have been adsorbed

563 onto the surface of the droplets, enhancing stability against flocculation and coalescence

564 and forming the white film observed in both microphotographs (Figs. 7b,d). On the other

565 hand, there are no noticeable differences between FMP and F/TMP samples with added $\kappa$ -

$566 \mathrm{C}$ and $\mathrm{XG}$ and oil, confirming that the addition of $\kappa-\mathrm{C}$ and $\mathrm{XG}$ significantly reduced 567 quality differences between FMP and their F/TMP counterparts.

\section{CONCLUSION}

571 The addition of either EVOO or cryoprotectants and processing significantly affected the 572 physical, structural and sensory characteristics of MP, although the effect of EVOO concentration depended on the presence of cryoprotectants and on freezing/thawing.

Increased EVOO concentration resulted in less structured systems and enhancement of color due to an increase in overall light scattering and pigment content. Addition of $\kappa$-C and XG improved thickness, possibly through the exclusion effect of swollen starch granules promoting gelation of the $\kappa$-C. Addition of EVOO in increasing concentrations enhanced the sensory quality of MP in terms of reduced granularity, denseness, cohesiveness, adhesiveness and fibrousness, and increased homogeneity, ease of swallowing and palate coating. Instrumental texture measurements were able to distinguish the variations in mechanical textural attributes scored by the panellists. Conversely, geometrical textural attributes (granularity, homogeneity and fibrousness) have to be support by structural traits. Creaminess was the most crucial factor for OA of the products and could be explained by the presence of EVOO aggregates observed by microstructure 
585 analysis. Samples with $50 \mathrm{~g} / \mathrm{kg}$ added EVOO were judged the best of all. There is a 586 possibility of using EVOO in combination with MP to provide a highly nutritious product 587 with improved physicochemical, functional and sensory characteristics.

588 


\section{ACKNOWLEDGEMENTS}

590

591 The authors wish to thank the Spanish Ministry of Science and Innovation for financial

592 support (AGL2007-62851), and P. Adeva, I. Amurrio and A. García of the Electron

593 Miscroscopy Laboratory (CENIM-CSIC).

594

595 


\section{REFERENCES}

597

598 ALVAREZ, M.D., FERNÁNDEZ, C. and CANET, W. 2005. Effect of freezing/thawing 599 conditions and long-term frozen storage on the quality of mashed potatoes. J. Food $600 \quad$ Agric. 85, 2327-2340.

601 ALVAREZ, M.D., CANET, W. and FERNÁNDEZ, C. 2008. Effect of addition of 602 biopolymers on the mechanical properties, colour and sensory attributes of fresh and 603 frozen/thawed mashed potatoes. Eur. Food Res. Technol. 226, 1525-1544.

604 ALVAREZ, M.D., FERNÁNDEZ, C. and CANET, W. 2009. Enhancement of freezing 605 stability in mashed potatoes by the incorporation of kappa-carrageenan and xanthan 606 gum blends. J. Sci. Food Agric. 89, 2115-2127.

607 ALVAREZ, M.D., FERNÁNDEZ, C. and CANET, W. Effect of cryoprotectant mixtures 608 on rheological properties of fresh and froze/thawed mashed potatoes J. Food Process 609 Eng. DOI: $10.1111 / \mathrm{j} .1745-4530.2008 .00350 . x$

610 AROCAS, A., SANZ, T. and FISZMAN, S.M. 2009. Improving effect of xanthan and 611 locust bean gums on the freeze-thaw stability of white sauces made with different 612 native starches. Food Hydrocolloids 23, 2478-2484.

613 AYUSO, J., HARO, M.R. and ESCOLAR, D. 2004. Simulation of the visible spectra for 614 edible virgin oils: Potential uses. Appl. Spectr. 7, 474-480.

615 BARANOWSKA, H.M., SIKORA, M., KOWALSKI, S. and TOMASIK, P. 2008. 616 Interactions of potato starch with selected polysaccharide hydrocolloids as measured by 617 low-field NMR. Food Hydrocolloids 22, 336-345.

618 BEMILLER, J.N. and WHISTLER, R.L. 1996. Carbohydrates. In Food chemistry (O.R. 619 Fennema, ed.) pp. 157-224, Marcel Dekker, New York. 
BOSKOU, D. and VISIOLI, F. 2003. Biophenols in olive oil and olives. In Bioavailability of micronutrients and minor dietary compounds. Metabolic and technological aspects (M.P. Vaquero, T. Garcia-Arias, A. Carbajal and F.J. Sanchez-Muniz, eds.) pp. 161169, Research Signpost, Kerala.

CAVELLA, S; DI MONACO, R., TORRIERI, E. and MASI, P. 2009. Structure of a new functional walnut oil-enriched mayonnaise. $9^{\text {th }}$ International Conference on Chemical and Progress Engineering, pts 1-3. Chemical Engineering Transactions 17, 879-884.

CHANTRAPORNCHAI, W., CLYDESDALE, F. and MCCLEMENTS, D.J. 1999. Influence of droplet characteristics on the optical properties of colored oil-in-water emulsions. Colloid Surface A 155, 373-382.

CHRISTIANSON, D.D., HODGE, J.E., OSBORNE, D. and DETROY, R.W. 1981. Gelatinization of wheat starch as modified by xanthan gum, guar gum, and cellulose gum. Cereal Chem. 58(6), 513-517.

CRIADO, M.N., ROMERO, M.P., CASANOVAS, M. and MOTILVA, M.J. 2008. Pigment profile and colour of monovarietal virgin olive oils from Arbequina cultivar obtained during two consecutive crop seasons. Food Chem. 110, 873-880.

DICKINSON, E. and CHEN, J.S. 1999. Heat-set whey protein emulsion gels: Role of active and inactive filler particles. J. Disper. Sci. Technol. 20, 197-213.

DE WIJK, R.A., VAN GEMERT, L.J., TERPSTRA, M.E.J. and WILKISON, C.L. 2003.

ELIASSON, A.C. and KIM, H.R. 1992. Changes in rheological properties of hydroxypropyl potato starch pastes during freeze-thaw treatments I. A rheological approach for evaluation of freeze-thaw stability. J. Texture Studies 23, 279-295. 
644 FERNÁNDEZ, C., ALVAREZ, M.D. and CANET, W. 2008. Steady shear and yield stress

645 of fresh and frozen/thawed mashed potatoes: effect of biopolymers addition. Food $646 \quad$ Hydrocolloids 22, 1381-1395.

647 FERNÁNDEZ, C., CANET, W. and ALVAREZ, M.D. 2009. Quality of mashed potatoes: 648 effect of adding blends of kappa-carrageenan and xanthan gum. Eur. Food Res. 649 Technol. 229, 205-222.

650 FERRERO, C., MARTINO, M.N. and Zaritzky, N.E. 1994. Corn starch-xanthan gum 651 interaction and its effect on the stability during storage of frozen gelatinized 652 suspensions. Starch-Stärke 46(8), 300-308.

653 GIANNOULI, P. and MORRIS, E.R. 2003. Cryogelation of xanthan. Food Hydrocolloids $654 \quad 17,495-501$.

655 ISO 8586-1: 1993. Sensory analysis - general guidance for the selection, training and 656 monitoring of assessors - part 1: selected assessors.

657 ISO 13299: 2003. Sensory analysis - Methodology - General guidance for establishing a 658 sensory profile.

659 JUSZACK, L., FORTUNA, T. and KOSLA, A. 2003. Sensory and rheological properties 660 of Polish commercial mayonnaises. Nahrung 47, 232-235.

661 KIM, H.R. and ELIASSON, A.C. 1993. Changes in rheological properties of 662 hydroxypropyl potato starch pastes during freeze-thaw treatments II. Effect of molar 663 substitution and cross-linking. J. Texture Studies 24, 199-213.

664 LAMBERTI, M., GEISELMANN, A., CONDE-PETIT, B. and ESCHER, F. 2004. Starch 665 transformation and structure development in production and reconstitution of potato $666 \quad$ flakes. LWT-Food Sci. Technol. 37, 417-427.

667 LIEHR, M. and KULICHE, W.M. 1996. Rheological examination of the influence of 668 hydrocolloids on the freeze-thaw-stability of starch gels. Starch-Stärke 48, 52-57. 
669 MANDALA, I.G. and PALOGOU, E.D. 2003. Effect of preparation conditions and 670 starch/xanthan concentration on gelation process of potato starch systems. Int. J. Food $671 \quad$ Prop. 6(2), 311-328.

672 MANDALA, I.G., SAVVAs, T.P. and KOSTAROPOULOS, A.E. 2004. Xanthan and 673 locust bean gum influence on the rheology and structure of a white model-sauce. J. $674 \quad$ Food Eng. 64, 335-342.

675

676

677

MILDNER-SZKUDLARZ, S and JELEŃ, H.H. 2010. Detection of olive oil adulteration with rapeseed and sunflower oils mos electronic nose and SMPE-MS. J. Food Qual 33, $21-41$

MUNIZ, F.J.S. 2007. Olive oil, life key in the Mediterranean area. Anales de la Real Academia Nacional de Farmacia 73(3), 653-692.

OSORIO, F.A. and STEFFE, J.F. 1987. Back extrusion of power law fluids. J. Texture Studies $18,43-63$.

PARASKEVOPOULOU, A., BOSKOU, D. and KIOSSEOGLOU, V. 2005. Stabilization of olive oil- lemon juice emulsion with polysaccharides. Food Chem. 90, 627-634.

PARKER, A., GUNNING, P.A., NG, K. and ROBINS, M.M. 1995. How does xanthan stabilise salad dressing? Food Hydrocolloids 9, 333-342.

SEVERINI, C., DE PILLI, T. and BAIANO, A. 2003. Partial substitution of pork backfat with extra-virgin olive oil in 'salami' products: effects on chemical, physical and sensorial quality. Meat Sci. 64, 323-331.

SUN, C. and GUNASEKARAN, S. 2009. Effects of protein concentration and oil-phase volume fraction on the stability and rheology of menhaden oil-in-water emulsions stabilized by whey protein isolate with xanthan gum. Food Hydrocolloids 23, 165-174.

SZCZESNIAK, A.S. 2002. Texture is a sensory property. Food Qual. Pref. 13, 215-225. 
693 UNE 87025, 1996. Manual de análisis sensorial. Tomo I-Alimentación. Aenor, Madrid, pp 694 167-186.

695 WHYBROW, S., HARRISON, C.L.S., MAYER, C. and STUBBS, R.J. 2006. Effects of 696 added fruits and vegetables on dietary intakes and body weight in Scottish adults. 697 British J. Nutr. 95, 496-503.

698 
700 FIG. 1. TEXTURAL PROPERTIES OF MASHED POTATOES WITH ADDED EXTRA 701 VIRGIN OLIVE OIL (EVOO)

702 (A-C) Firmness; (D-F) Average force; MPA, MPB: mashed potatoes without and with 703 added cryoprotectants respectively; FMP, F/TMP: fresh and frozen/thawed mashed 704 potatoes respectively.

705 FIG. 2. COLOR PARAMETERS AND EXPRESSIBLE WATER OF MASHED 706 POTATOES WITH ADDED EXTRA VIRGIN OLIVE OIL (EVOO)

(A-C) L*, lightness; $\mathrm{a}^{*}$, red-greeness; YI, yellowness index; (D) $\mathrm{E}_{\mathrm{w}}$, expressible water; 708 MPA, MPB: mashed potatoes without and with added cryoprotectants respectively; FMP, 709 F/TMP: fresh and frozen/thawed mashed potatoes respectively.

FIG. 3. TPA SENSORY ATTRIBUTES OF MASHED POTATOES WITH ADDED 711 EXTRA VIRGIN OLIVE OIL (EVOO)

(A, B) Granularity; (C) Moisture (1); (D) Stickiness; (E, F) Denseness; (G, H)

713 Homogeneity; (I) Moisture (2); MPA, MPB: mashed potatoes without and with added 714 cryoprotectants respectively; FMP, F/TMP: fresh and frozen/thawed mashed potatoes 715 respectively. FIG. 4. TPA SENSORY ATTRIBUTES OF MASHED POTATOES WITH ADDED EXTRA VIRGIN OLIVE OIL (EVOO)

718 (A, B) Firmness; (C) Cohesiveness; (D, E) Adhesiveness; (F, G) Fibrousness (1); (H, I) 719 Ease of swallowing; MPA, MPB: mashed potatoes without and with added cryoprotectants 720 respectively; FMP, F/TMP: fresh and frozen/thawed mashed potatoes respectively. FIG. 5. TPA SENSORY ATTRIBUTES AND OVERALL ACCEPTABILITY OF 
723 (A-C) Palate coating; (D) Fibrousness (2); (E, F) Overall acceptability (OA); MPA, MPB:

724 mashed potatoes without and with added cryoprotectants respectively; FMP, F/TMP: fresh

725 and frozen/thawed mashed potatoes respectively.

726 FIG. 6. MICROPHOTOGRAPHS OF MASHED POTATOES

727 (A) Fresh sample without added cryoprotectants; (B) Fresh sample with added

728 cryoprotectants; (C) Processed sample without added cryoprotectants; (D) Processed

729 sample with added cryoprotectants; Magnification was 200 (bar $=100 \mu \mathrm{m})$.

730 FIG. 7. MICROPHOTOGRAPHS OF MASHED POTATOES WITH ADDED EXTRA

731 VIRGIN OLIVE OIL (EVOO)

732 (A) Fresh sample without added cryoprotectants and with $50 \mathrm{~g} / \mathrm{kg}$ added EVOO; (B) Fresh 733 sample with added cryoprotectants and with $50 \mathrm{~g} / \mathrm{kg}$ added EVOO; (C) Processed sample 734 without added cryoprotectants and with $50 \mathrm{~g} / \mathrm{kg}$ added EVOO; (D) Processed sample with 735 added cryoprotectants and with $50 \mathrm{~g} / \mathrm{kg}$ added EVOO; Magnification was 200 (bar = 100 $736 \mu \mathrm{m})$.

737 


\section{FIGURE 1}
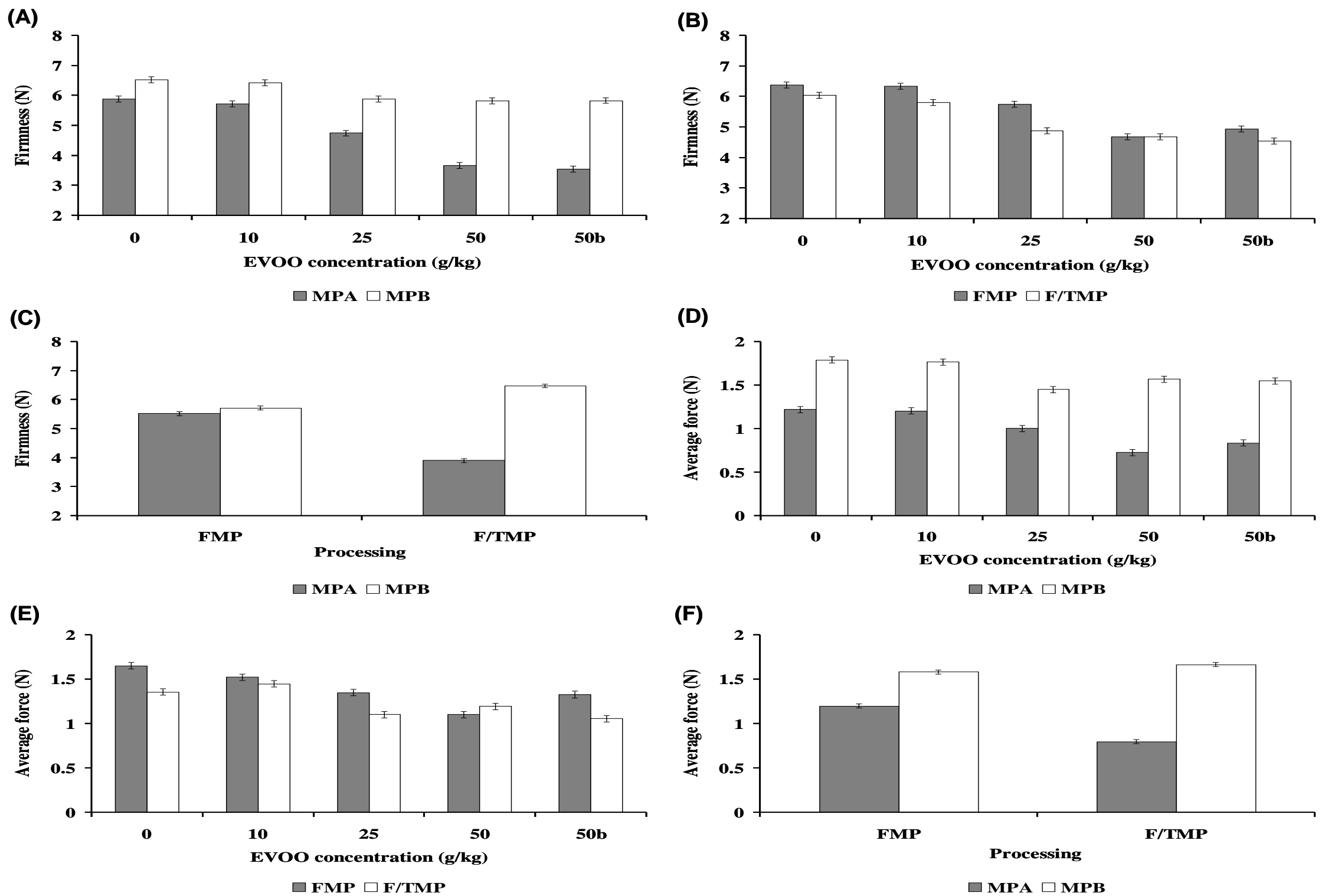
FIGURE 2

(A)

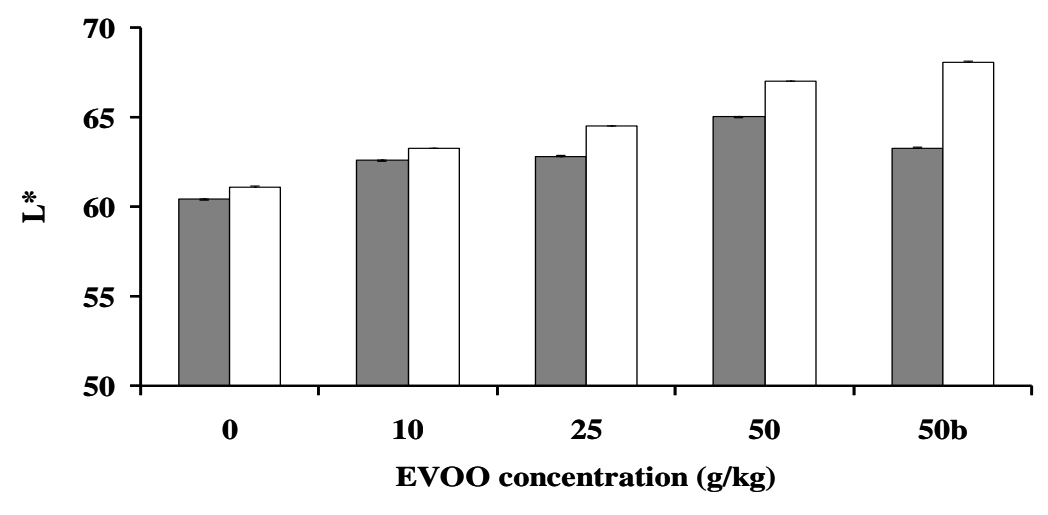

(C)

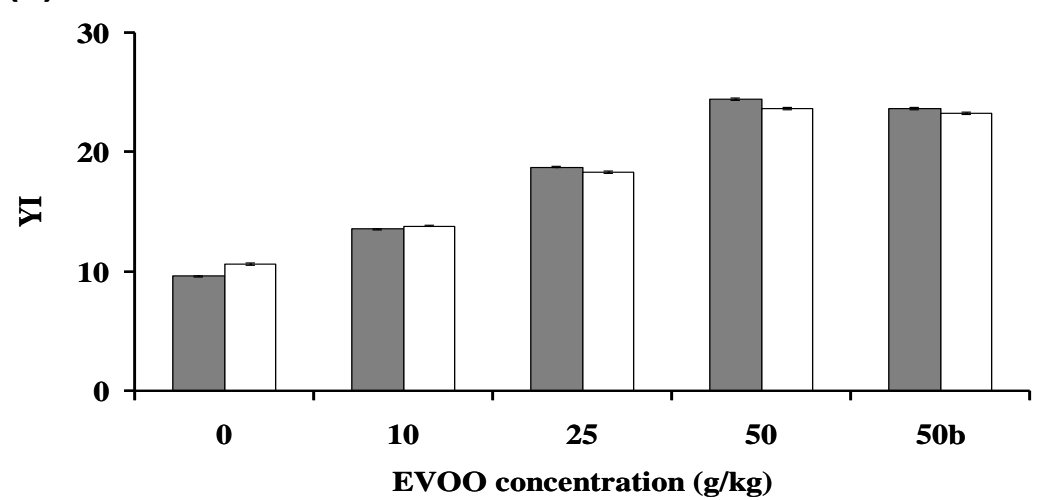

$\square$ FMP $\square$ F/TMP
(B)

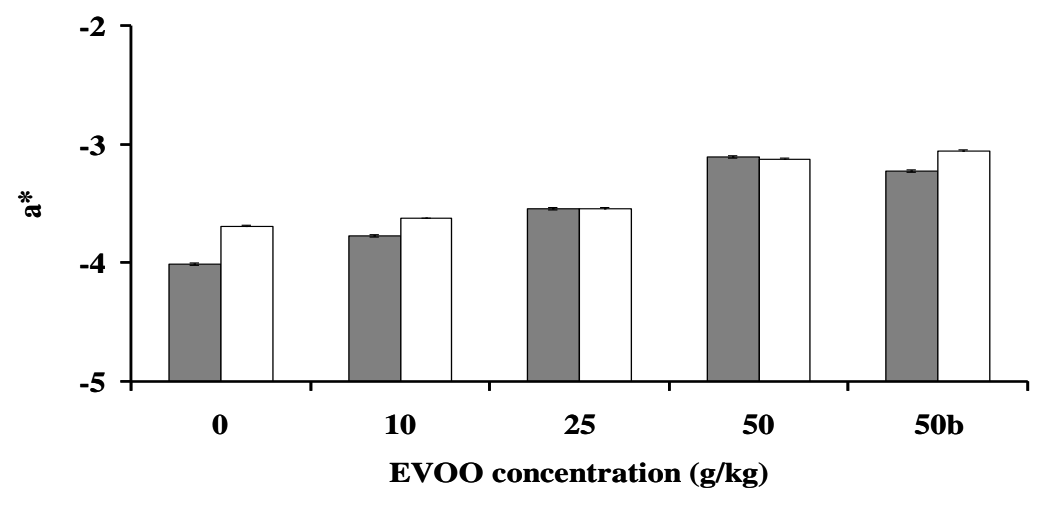

(D)

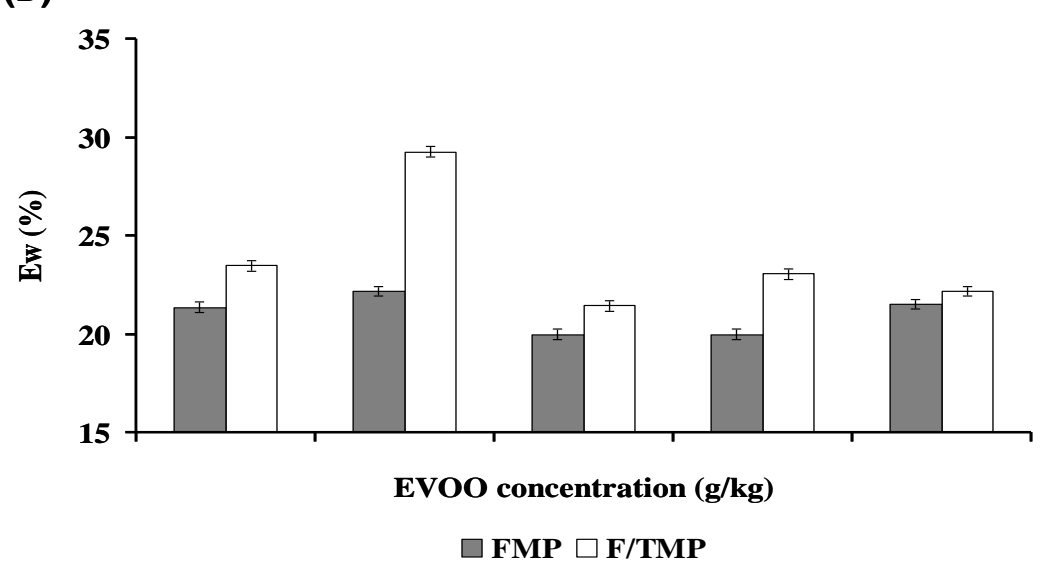




\section{FIGURE 3}
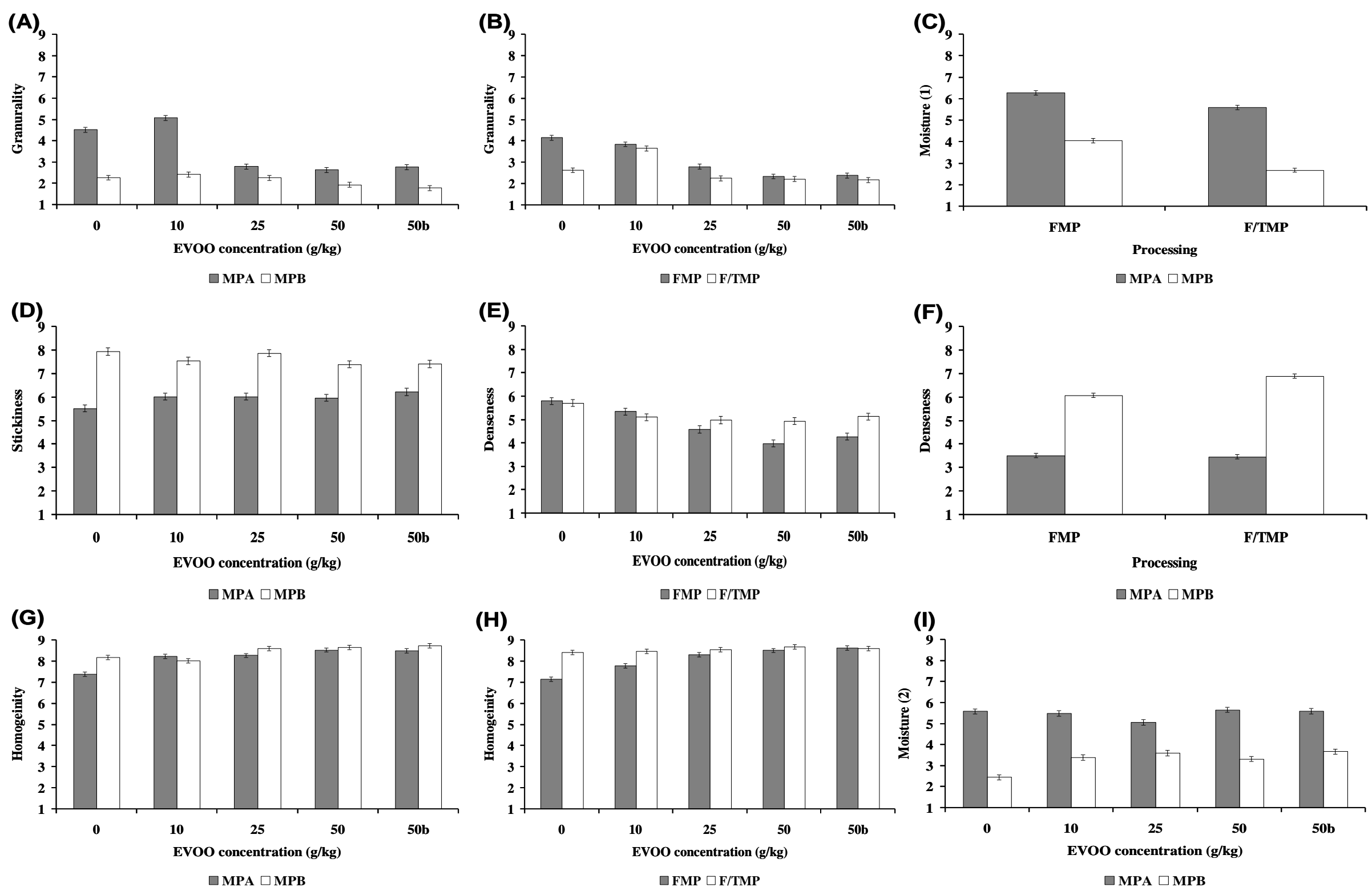
FIGURE 4

(A)

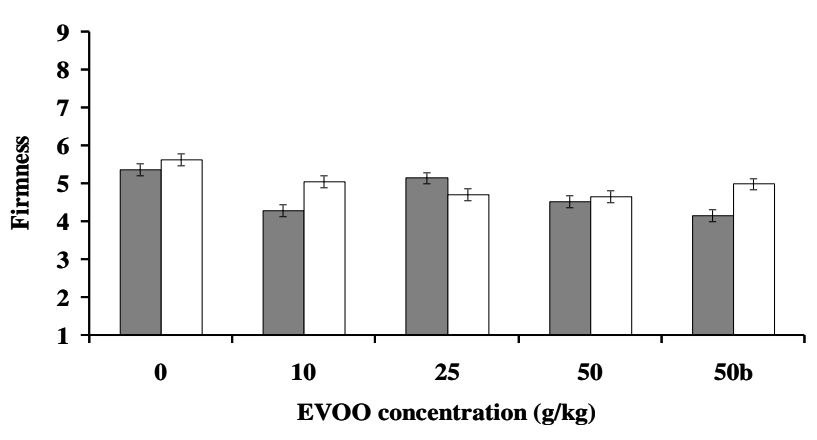

(D)

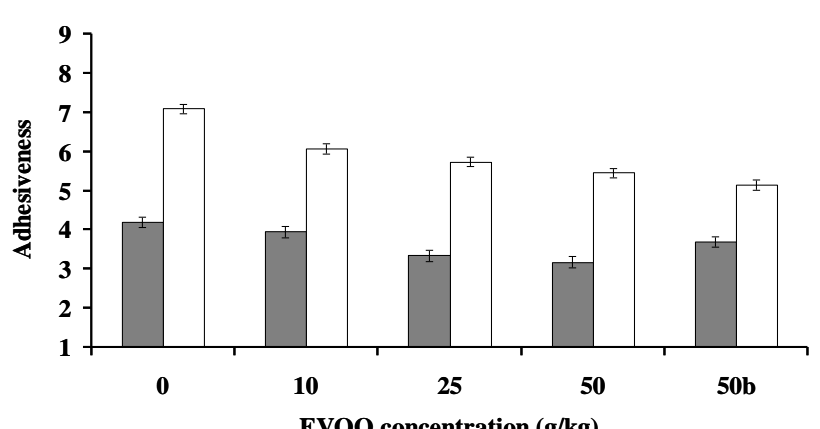

(G)

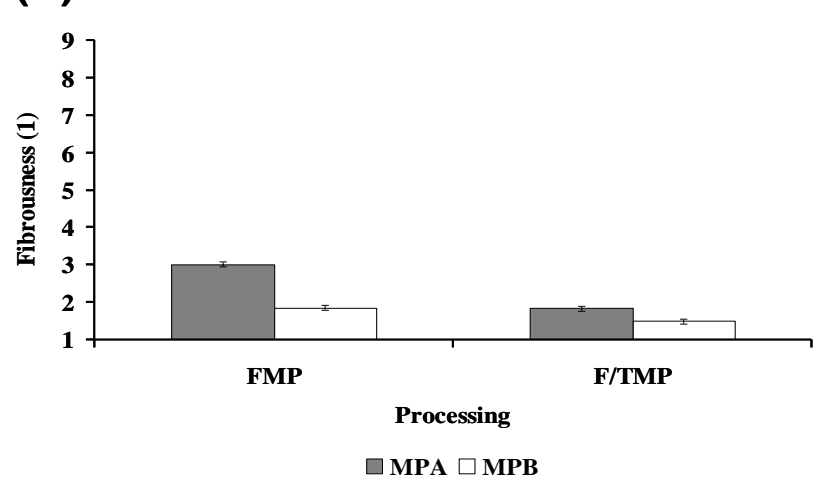

(B)

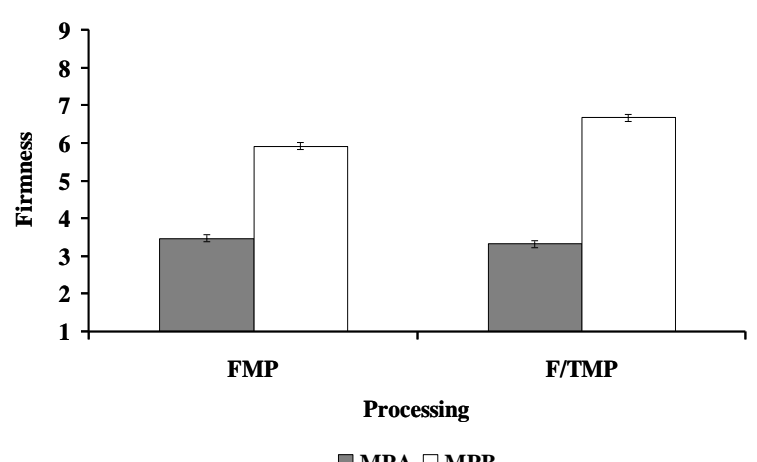

(E)

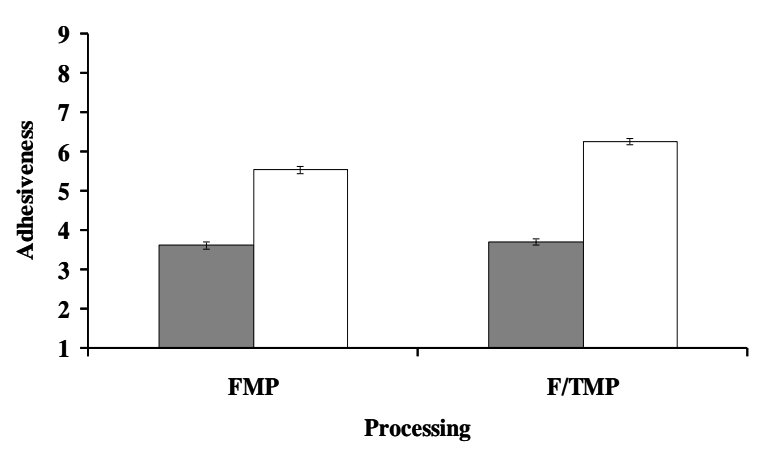

(H)

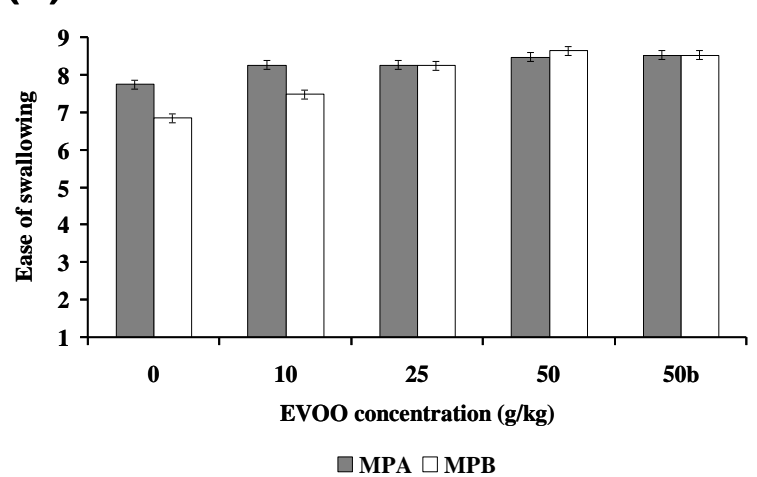

(C)

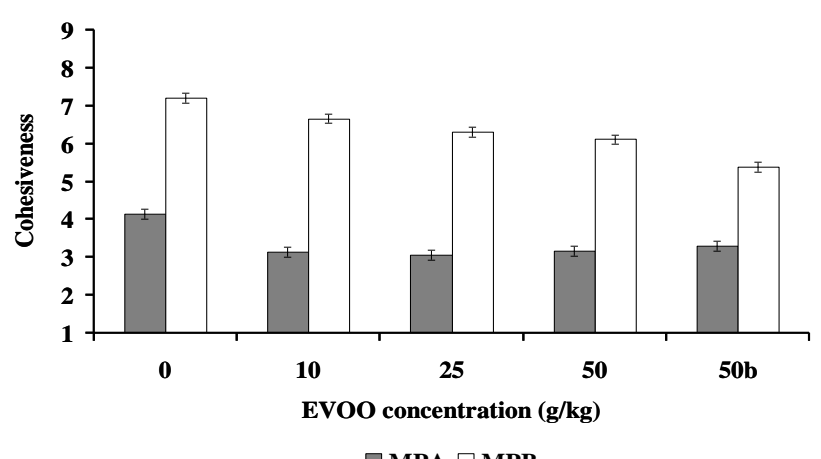

(F)

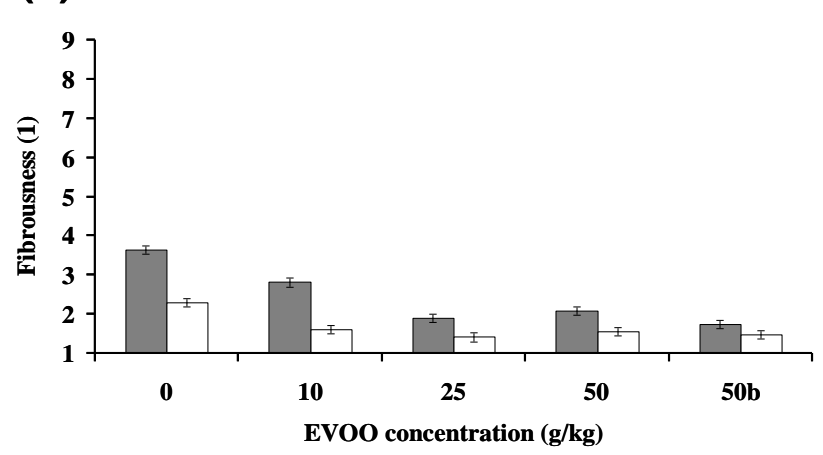

(I)

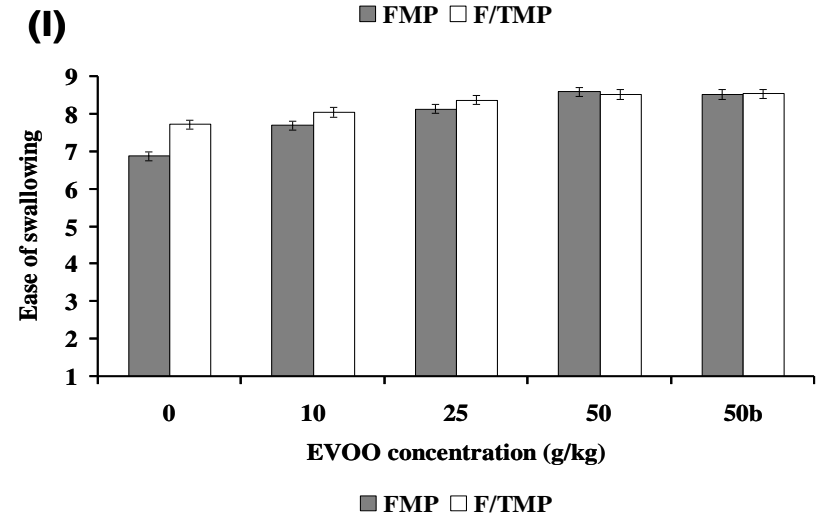


FIGURE 5

(A)

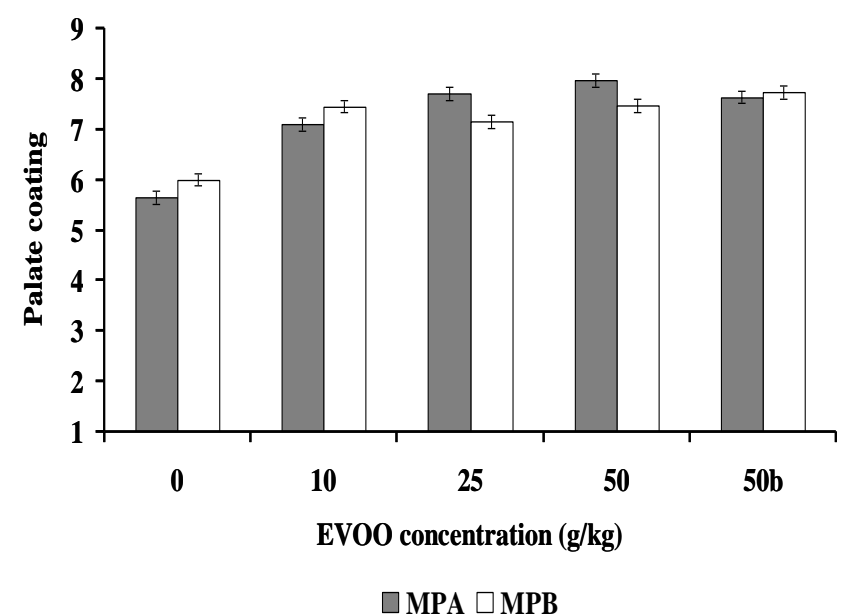

(D)

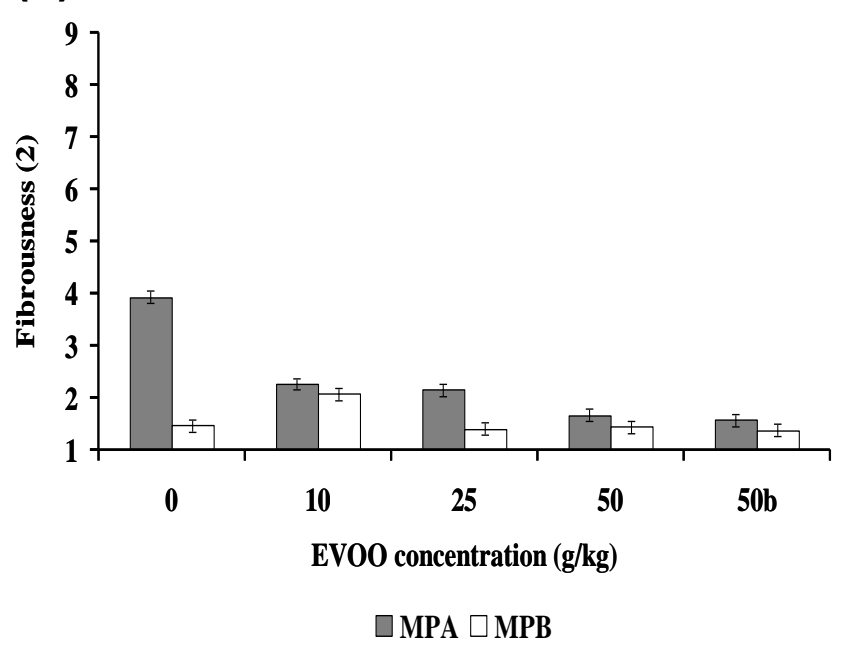

(B)

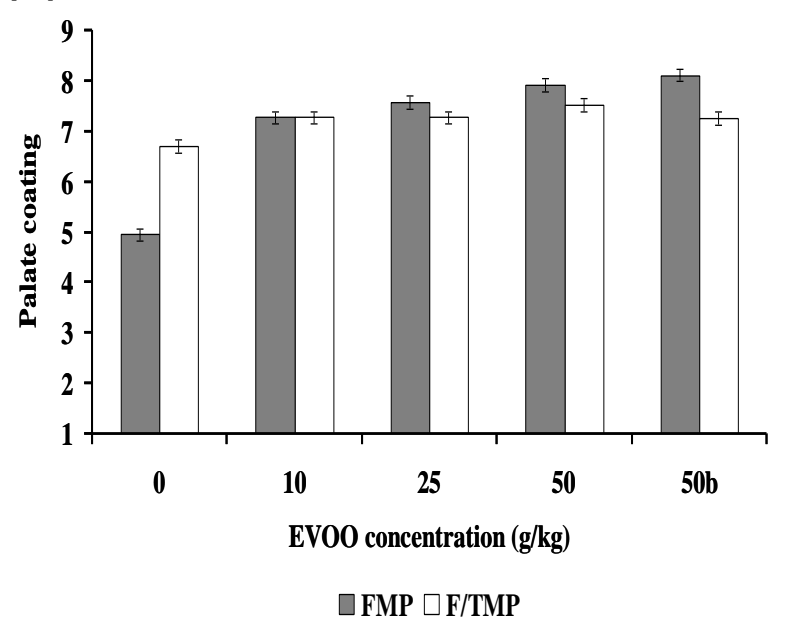

(E)

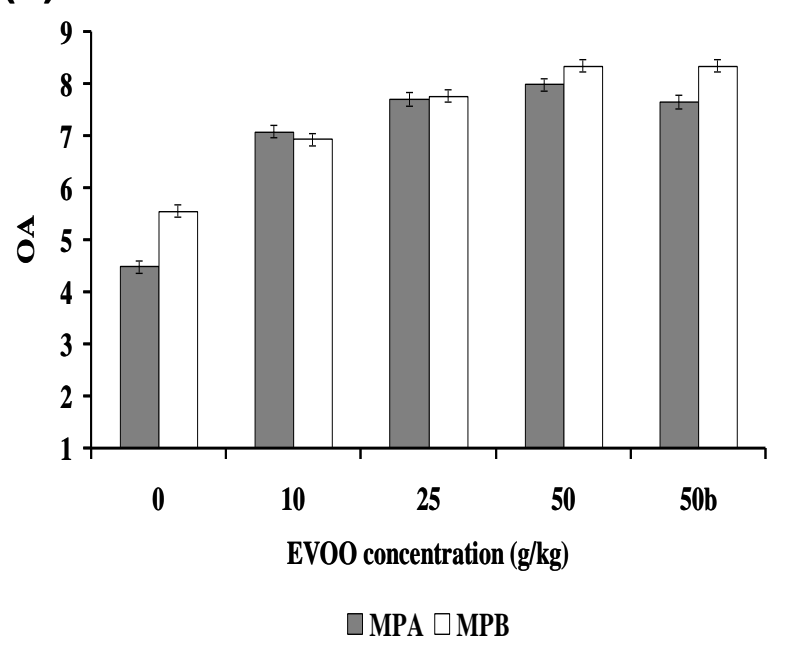

(C)

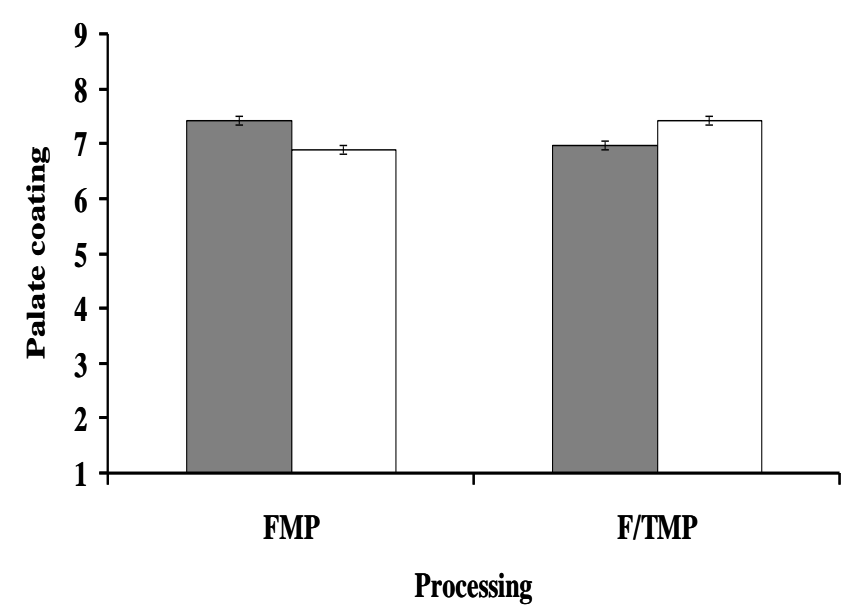

(F)
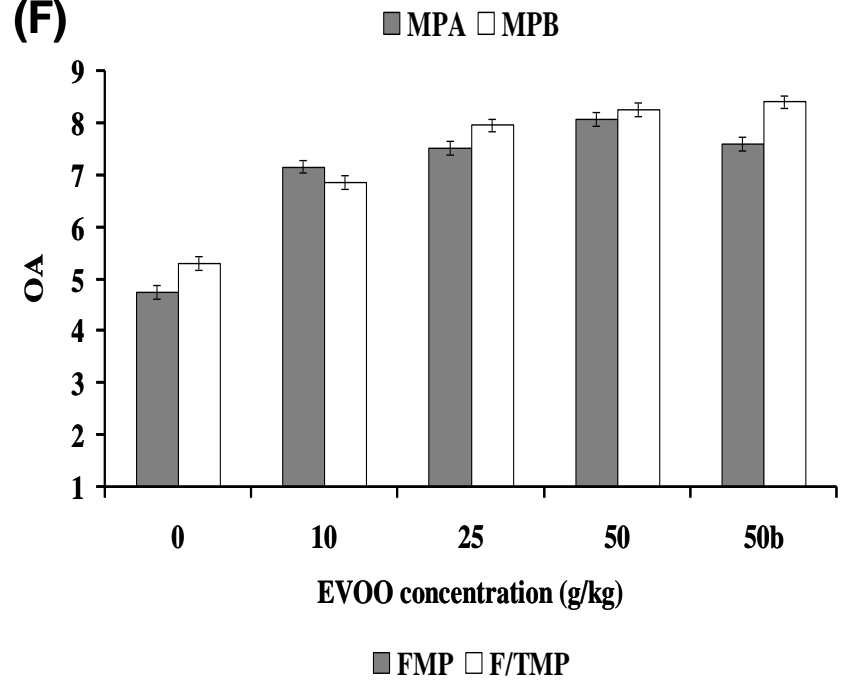
TABLE 1. EFFECTS OF EVOO CONCENTRATION, CRYOPROTECTANT ADDITION AND FREEZING/THAWING ON TEXTURAL PROPERTIES OF MP

\begin{tabular}{|c|c|c|c|c|}
\hline Source & $\begin{array}{l}\text { Firmness } \\
(\mathrm{N})\end{array}$ & $\begin{array}{l}\text { Viscosity } \\
\text { index (N s) }\end{array}$ & $\begin{array}{l}\text { Work per } \\
\text { displaced } \\
\text { volume } \\
\left(\mathrm{J} / \mathrm{m}^{3}\right)\end{array}$ & $\begin{array}{l}\text { Average } \\
\text { force }(\mathrm{N})\end{array}$ \\
\hline \multicolumn{5}{|l|}{ Main effects: } \\
\hline \multicolumn{5}{|c|}{ A:EVOO concentration $(\mathrm{g} / \mathrm{kg})$} \\
\hline 0 & $6.21 \mathrm{a}$ & $-29.33 \mathrm{a}$ & $3518.78 \mathrm{a}$ & $1.51 \mathrm{a}$ \\
\hline 10 & $6.08 \mathrm{a}$ & $-28.37 \mathrm{a}$ & $3462.25 \mathrm{a}$ & $1.49 \mathrm{a}$ \\
\hline 25 & $5.32 \mathrm{~b}$ & $-26.12 b$ & $2867.16 \mathrm{~b}$ & $1.23 \mathrm{~b}$ \\
\hline 50 & $4.69 \mathrm{c}$ & $-23.06 c$ & $2681.10 \mathrm{~b}$ & $1.15 \mathrm{~b}$ \\
\hline $50 \mathrm{~b}$ & $4.74 \mathrm{c}$ & $-23.69 c$ & $2786.29 \mathrm{~b}$ & $1.19 \mathrm{~b}$ \\
\hline$P$ values & $<0.001$ & $<0.001$ & $<0.001$ & $<0.001$ \\
\hline $\operatorname{LSD}(99 \%)$ & 0.26 & 1.24 & 227.00 & 0.097 \\
\hline \multicolumn{5}{|c|}{ B:Cryoprotectant addition } \\
\hline Without $\kappa$-C and $\mathrm{XG}$ & $4.71 \mathrm{a}$ & $-20.71 \mathrm{a}$ & $2333.51 \mathrm{a}$ & $1.00 \mathrm{a}$ \\
\hline With $\kappa-\mathrm{C}$ and $\mathrm{XG}$ & $6.10 \mathrm{~b}$ & $-31.52 b$ & $3792.72 \mathrm{~b}$ & $1.63 \mathrm{~b}$ \\
\hline$P$ values & $<0.001$ & $<0.001$ & $<0.001$ & $<0.001$ \\
\hline$L S D(99 \%)$ & 0.16 & 0.78 & 143.57 & 0.06 \\
\hline \multicolumn{5}{|l|}{$\mathrm{C}:$ Processing } \\
\hline Fresh & $5.62 \mathrm{a}$ & $-26.73 \mathrm{a}$ & $3248.00 \mathrm{a}$ & $1.39 \mathrm{a}$ \\
\hline Frozen/thawed & $5.19 \mathrm{~b}$ & $-25.50 b$ & $2878.23 \mathrm{~b}$ & $1.23 \mathrm{~b}$ \\
\hline$P$ values & $<0.001$ & $<0.001$ & $<0.001$ & $<0.001$ \\
\hline LSD (99\%) & 0.16 & 0.78 & 143.57 & 0.06 \\
\hline \multicolumn{5}{|l|}{ Interactions } \\
\hline $\mathrm{AB}$ & $<0.001$ & $<0.001$ & $<0.001$ & $<0.001$ \\
\hline $\mathrm{AC}$ & 0.001 & 0.18 & $<0.001$ & $<0.001$ \\
\hline $\mathrm{BC}$ & $<0.001$ & $<0.001$ & $<0.001$ & $<0.001$ \\
\hline $\mathrm{ABC}$ & $<0.001$ & $<0.001$ & $<0.001$ & $<0.001$ \\
\hline
\end{tabular}


TABLE 2. EFFECTS OF EVOO CONCENTRATION, CRYOPROTECTANT ADDITION AND FREEZING/THAWING ON COLOR MEASUREMENTS AND EXPRESSIBLE WATER OF MP

\begin{tabular}{|c|c|c|c|c|}
\hline Source & $L^{*}$ & $a^{*}$ & YI & $E_{\mathrm{w}}(\%)$ \\
\hline \multicolumn{5}{|l|}{ Main effects: } \\
\hline \multicolumn{5}{|c|}{ A:EVOO concentration $(\mathrm{g} / \mathrm{kg})$} \\
\hline 0 & $60.79 \mathrm{a}$ & $-3.85 a$ & $10.14 \mathrm{a}$ & $22.42 \mathrm{~b}$ \\
\hline 10 & $62.95 \mathrm{~b}$ & $-3.70 b$ & $13.73 \mathrm{~b}$ & $25.73 \mathrm{a}$ \\
\hline 25 & $63.68 \mathrm{c}$ & $-3.54 c$ & $18.58 \mathrm{c}$ & $20.72 \mathrm{~d}$ \\
\hline 50 & $66.04 \mathrm{~d}$ & $-3.11 \mathrm{~d}$ & $24.08 \mathrm{~d}$ & $21.52 \mathrm{c}$ \\
\hline $50 \mathrm{~b}$ & $65.70 \mathrm{e}$ & $-3.14 \mathrm{~d}$ & $23.47 \mathrm{e}$ & $21.85 \mathrm{~b}, \mathrm{c}$ \\
\hline$P$ values & $<0.001$ & $<0.001$ & $<0.001$ & $<0.001$ \\
\hline $\operatorname{LSD}(99 \%)$ & 0.07 & 0.02 & 0.20 & 0.71 \\
\hline \multicolumn{5}{|c|}{ B:Cryoprotectant addition } \\
\hline Without $\kappa-\mathrm{C}$ and $\mathrm{XG}$ & $62.85 \mathrm{a}$ & $-3.59 a$ & $16.74 \mathrm{a}$ & - \\
\hline With $\kappa-\mathrm{C}$ and $\mathrm{XG}$ & $64.81 \mathrm{~b}$ & $-3.34 b$ & $19.26 \mathrm{~b}$ & - \\
\hline$P$ values & $<0.001$ & $<0.001$ & $<0.001$ & - \\
\hline $\operatorname{LSD}(99 \%)$ & 0.04 & 0.01 & 0.13 & - \\
\hline \multicolumn{5}{|l|}{$\mathrm{C}:$ Processing } \\
\hline Fresh & $63.33 \mathrm{a}$ & $-3.53 a$ & $18.03 \mathrm{a}$ & $21.01 \mathrm{a}$ \\
\hline Frozen/thawed & $64.33 \mathrm{~b}$ & $-3.40 b$ & $17.97 \mathrm{a}$ & $23.89 \mathrm{~b}$ \\
\hline$P$ values & $<0.001$ & $<0.001$ & 0.17 & $<0.001$ \\
\hline LSD (99\%) & 0.04 & 0.01 & 0.13 & 0.45 \\
\hline \multicolumn{5}{|l|}{ Interactions } \\
\hline $\mathrm{AB}$ & $<0.001$ & $<0.001$ & $<0.001$ & - \\
\hline $\mathrm{AC}$ & $<0.001$ & $<0.001$ & $<0.001$ & $<0.001$ \\
\hline $\mathrm{BC}$ & $<0.001$ & 0.34 & $<0.001$ & - \\
\hline $\mathrm{ABC}$ & $<0.001$ & $<0.001$ & $<0.001$ & - \\
\hline
\end{tabular}


TABLE 3. EFFECTS OF EVOO CONCENTRATION, CRYOPROTECTANT ADDITION AND FREEZING/THAWING ON SENSORY ATTRIBUTES PERCEIVED BEFORE AND AT THE TIME OF PUTTING THE SAMPLE IN THE MOUTH, AND AT THE TIME OF PREPARING THE SAMPLE FOR SWALLOWING OF MP

\begin{tabular}{|c|c|c|c|c|c|c|c|c|c|c|}
\hline \multirow{2}{*}{$\begin{array}{l}\text { Sensory attributes } \\
\text { Source } \\
\end{array}$} & \multicolumn{2}{|c|}{$\begin{array}{l}\text { Perceived before putting } \\
\text { the sample in the mouth }\end{array}$} & \multicolumn{5}{|c|}{ Perceived at the time of putting the sample in the mouth } & \multicolumn{3}{|c|}{$\begin{array}{l}\text { Perceived at the time of preparing the sample } \\
\text { for swallowing }\end{array}$} \\
\hline & Granularity & Moisture (1) & Stickiness & Denseness & Homogeneity & Moisture (2) & Firmness & Cohesiveness & Adhesiveness & Fibrousness (1) \\
\hline \multicolumn{11}{|l|}{ Main effects: } \\
\hline A:EVOO concentration & $<0.001$ & 0.022 & 0.487 & $<0.001$ & $<0.001$ & $<0.001$ & $<0.001$ & $<0.001$ & $<0.001$ & $<0.001$ \\
\hline B:Cryoprotectant addition & $<0.001$ & $<0.001$ & $<0.001$ & $<0.001$ & $<0.001$ & $<0.001$ & $<0.001$ & $<0.001$ & $<0.001$ & $<0.001$ \\
\hline $\mathrm{C}:$ Processing & $<0.001$ & $<0.001$ & 0.542 & $<0.001$ & $<0.001$ & $<0.001$ & 0.002 & 0.002 & $<0.001$ & $<0.001$ \\
\hline \multicolumn{11}{|l|}{ Interactions } \\
\hline $\mathrm{AB}$ & $<0.001$ & 0.002 & 0.002 & 0.236 & $<0.001$ & $<0.001$ & 0.044 & $<0.001$ & $<0.001$ & $<0.001$ \\
\hline $\mathrm{AC}$ & $<0.001$ & 0.003 & $<0.001$ & $<0.001$ & $<0.001$ & 0.082 & $<0.001$ & 0.292 & 0.818 & $<0.001$ \\
\hline $\mathrm{BC}$ & 0.015 & 0.001 & 0.611 & $<0.001$ & 0.970 & 0.003 & $<0.001$ & 0.083 & $<0.001$ & $<0.001$ \\
\hline $\mathrm{ABC}$ & $<0.001$ & $<0.001$ & $<0.001$ & 0.143 & $<0.001$ & $<0.001$ & $<0.001$ & $<0.001$ & $<0.001$ & $<0.001$ \\
\hline
\end{tabular}


TABLE 4. EFFECTS OF EVOO CONCENTRATION, CRYOPROTECTANT ADDITION AND FREEZING/THAWING ON SENSORY ATTRIBUTES PERCEIVED DURING THE FINAL AND RESIDUAL PHASES OF MASTICATION AND OVERALL ACCEPTABILITY OF MP

\begin{tabular}{|c|c|c|c|c|}
\hline Sensory attributes & \multicolumn{3}{|c|}{$\begin{array}{l}\text { Perceived during the final and residual phases of } \\
\text { mastication }\end{array}$} & \multirow[t]{2}{*}{$\begin{array}{c}\text { Overall } \\
\text { acceptability } \\
\text { (OA) }\end{array}$} \\
\hline Source & $\begin{array}{l}\text { Ease of } \\
\text { swallowing }\end{array}$ & $\begin{array}{l}\text { Palate } \\
\text { coating }\end{array}$ & Fibrousness (2) & \\
\hline \multicolumn{5}{|l|}{ Main effects: } \\
\hline A:EVOO concentration & $<0.001$ & $<0.001$ & $<0.001$ & $<0.001$ \\
\hline B:Cryoprotectant addition & $<0.001$ & 0.520 & $<0.001$ & $<0.001$ \\
\hline C:Processing & $<0.001$ & 0.601 & $<0.001$ & $<0.001$ \\
\hline \multicolumn{5}{|l|}{ Interactions } \\
\hline $\mathrm{AB}$ & $<0.001$ & $<0.001$ & $<0.001$ & $<0.001$ \\
\hline $\mathrm{AC}$ & 0.003 & $<0.001$ & $<0.001$ & $<0.001$ \\
\hline $\mathrm{BC}$ & 0.126 & $<0.001$ & $<0.001$ & 0.055 \\
\hline $\mathrm{ABC}$ & 0.211 & $<0.001$ & $<0.001$ & 0.015 \\
\hline
\end{tabular}


FIGURE 6

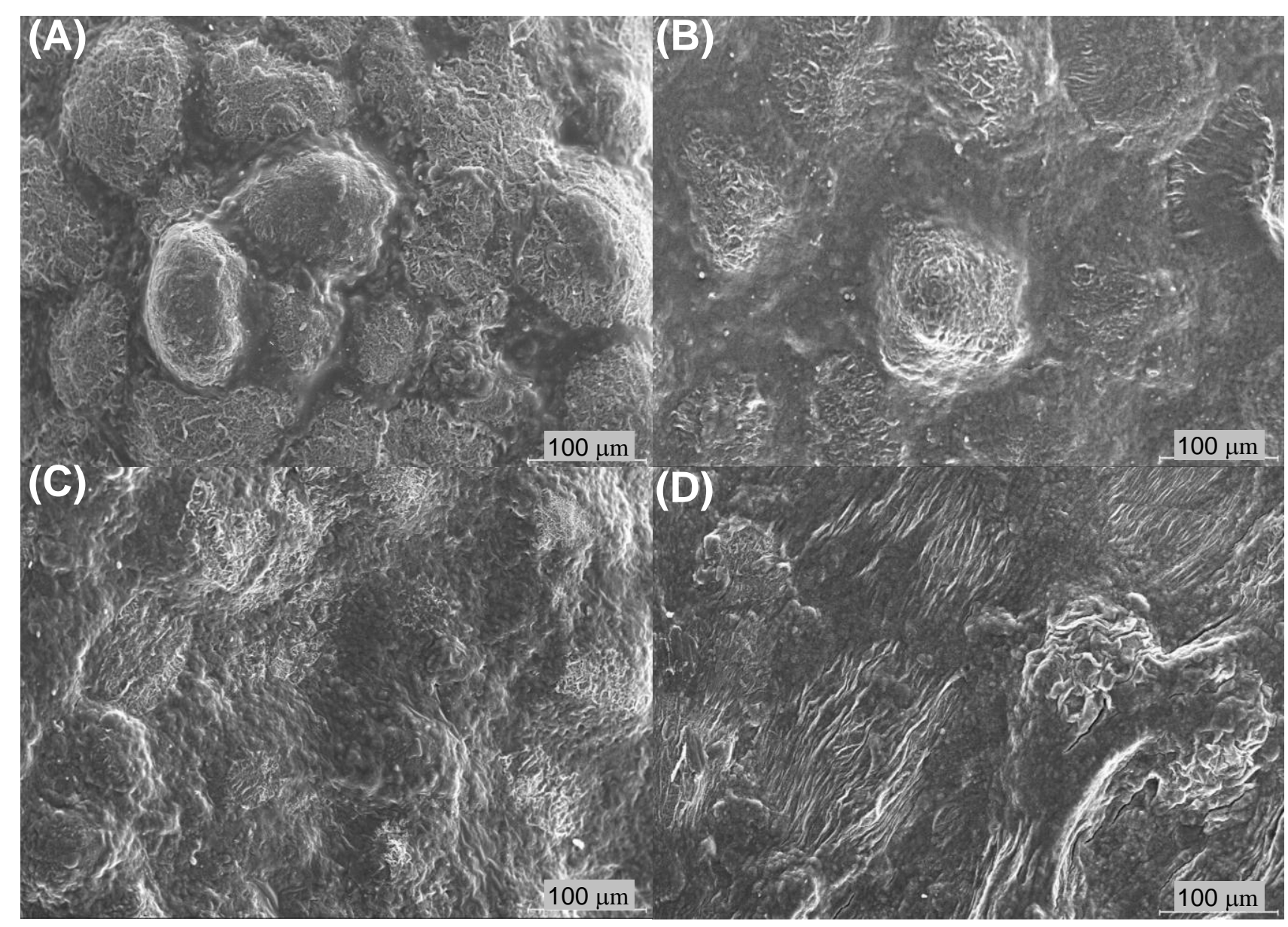




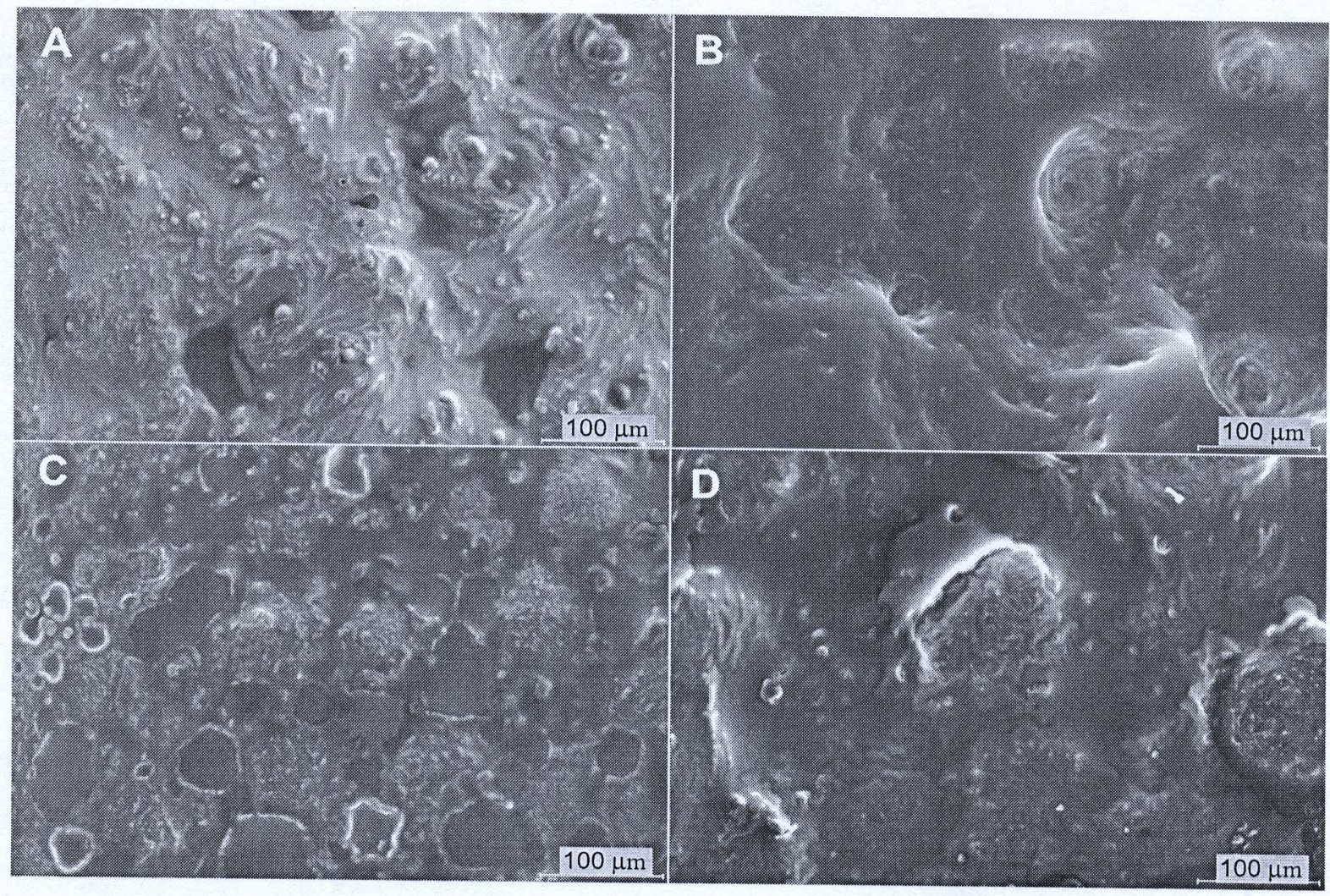

FIG. 7. MICROPHOTOGRAPHS OF MASHED POTATOES WITH ADDED EXTRA VIRGIN OLIVE OIL (EVOO)

(A) Fresh sample without added cryoprotectants and with $50 \mathrm{~g} / \mathrm{kg}$ added EVOO; (B) Fresh sample with added cryoprotectants and with $50 \mathrm{~g} / \mathrm{kg}$ added EVOO; (C) Processed sample without added cryoprotectants and with $50 \mathrm{~g} / \mathrm{kg}$ added EVOO; (D) Processed sample with added cryoprotectants and with $50 \mathrm{~g} / \mathrm{kg}$ added EVOO; Magnification was $200(\mathrm{bar}=100 \mu \mathrm{m})$ 